\title{
ANALYSIS OF NOTCH EFFECT IN LOAD BEARING CAPACITY, APPARENT FRACTURE TOUGHNESS AND FRACTURE MICROMECHANISMS OF FERRITIC- PEARLITIC STEELS
}

\author{
S. Cicero, T. García, V. Madrazo, I.A. Carrascal, E. Ruiz
}

Dpto. Ciencia e Ingeniería del Terreno y de los Materiales, Universidad de Cantabria, Av/ Los Castros s/n, 39005, Santander, Cantabria, Spain, ciceros@unican.es

\begin{abstract}
This paper presents the analysis of the notch effect in two ferritc-pearlitic steels: S275JR and $\mathrm{S} 355 \mathrm{~J} 2$. The research is based on the development and analysis of an experimental programme composed of $336 \mathrm{CT}$ specimens, combining 6 different notch radii, and testing temperatures from the lower shelf up to the upper shelf of the two materials. The notch effect is analysed through the evolution of both the load bearing capacity and the apparent fracture toughness, and also through the relation between these two variables and the failure micromechanisms.
\end{abstract}

The results reveal a clear notch effect in both materials. In the case of the load bearing capacity, this notch effect has its maximum at lower shelf temperatures. The notch effect in the apparent fracture presents a maximum at the lower temperatures of the ductile-to-brittle transition zone. Finally, the Scanning Electron Microscopy fractographies have justified the previous observations.

Keywords: Notch effect, load bearing capacity, apparent fracture toughness, fracture micromechanisms

\section{INTRODUCTION}

Notch-type defects generate less demanding stress fields than crack-like defects. Numerous papers may be found in the literature providing different models of the stress field in the notch tip (e.g., [1-10]). Basically, they all suggestprovide mathematical expressions implying a reduction of the stress acting perpendicular to the notch plane, in such a way that the larger the notch radius the more significant the stress reduction. This generally has direct consequences on the resistant behaviour of structural components (e.g., [10-19]). Comprehensive reviews of this phenomenon covering thousands of experimental data may be found in $[15,16,19]$, whereas specific results for particular materials may be found in, for example, [13] (ceramics), [14] (alumina and soda-lime glass), [17] (PMMA) and [18] (Al7075-T651). Thus, in most cases, a given component has a higher load bearing capacity in notched conditions than in cracked conditions. On some occasions, however, sharp notches behave like cracks and also blunt notches may not penalise the load bearing capacity (beyond the corresponding reduction of the resistant section). Additionally, the terms "sharp" and "blunt" are not absolute, but rather they depend on the material: there are materials that present a clear notch effect (e.g., increase in load bearing capacity) for very small notch radii (e.g, [18]), and there are others that require a certain notch radius to develop a notch effect (e.g., [17]). 
This particular nature of notches has led to a great deal of research work over the last few decades, aiming to provide specific tools for the assessment of notched components, beyond the simple and generally overconservative application of ordinary fracture mechanics.

There are two main failure criteria in notch theory: the global fracture criterion and local fracture criteria [1ㅁ,13]. The global criterion establishes that failure occurs when the notch stress intensity factor reaches a critical value, $\mathrm{K}_{\rho}{ }^{\mathrm{c}}$, which depends on the notch radius and the material:

$$
\mathrm{K}_{\rho}=\mathrm{K}_{\rho}^{\mathrm{c}}
$$

where $K_{\rho}$ defines the stress and strain fields in the vicinity of the notch tip (analogously to $K_{I}$ in the crack tip). This approach, of an unquestionable significance, is totally analogous to that used in cracks, but its application is very limited because of the lack of analytical solutions for $\mathrm{K}_{\rho}$ (in contrast with the case of $\mathrm{K}_{\mathrm{I}}$, e.g., [18 2120-23]) or/and standardised procedures for the experimental definition of $\mathrm{K}_{\rho}^{\mathrm{c}}$ (in contrast with the case of $\mathrm{K}_{\mathrm{IC}}$, e.g., [24]). Moreover, the existing solutions are mainly focussed in $\mathrm{V}$-shaped notches, such as those proposed in [25, $\underline{26}]$ for sharp V-shaped notches (zero notch radius), and [27] for both sharp and blunted V-shaped notches.

Concerning local criteria, these are based on the stress-strain field at the notch tip and can be more widely applied than global criteria from a practical point of view. Among them, the Point Method (PM) and the Line Method (LM) [15] are of particular practical significance, being different versions of the Theory of Critical Distances (TCD), which also includes methodologies such as the Imaginary Crack Method, the Area Method and the Volume Method [15]. In both cases, a characteristic material length parameter (the critical distance, L) is used when performing fracture assessments [15]:

$$
L=\frac{1}{\pi}\left(\frac{K_{I C}}{\sigma_{0}}\right)^{2}
$$

where $\mathrm{K}_{\mathrm{IC}}$ is the material fracture toughness (cracked conditions) and $\sigma_{0}$ is a characteristic material strength parameter, usually larger than the ultimate tensile strength $\left(\sigma_{u}\right)$, that must be calibrated. The notch analysis following these methodologies is relatively simple: the PM establishes that fracture occurs when the stress reaches the inherent strength $\left(\sigma_{0}\right)$ at a distance from the defect tip equal to $L / 2$ :

$$
\sigma\left(\frac{L}{2}\right)=\sigma_{0}
$$

For its part, the LM assumes that fracture occurs when the average stress along a distance equal to $2 \mathrm{~L}$ (starting from the defect tip), reaches the inherent strength, $\sigma_{0}$ :

$$
\frac{1}{2 L} \int_{0}^{2 L} \sigma(r) d r=\sigma_{0}
$$


Moreover, as mentioned above, the notch effect modifies the stress field at the notch tip, and therefore it is actually a source of loss of constraint (e.g., [28-34]). This has led to notch analyses based on two parameter fracture mechanics, especially those based on the T-stress (e.g., $[\underline{35}, \underline{36}]$ ). However, analogously to notch global approaches, its practical applications when analysing the notch effect and the structural integrity of components containing notches are limited, given that these methodologies are basically focused on crack-like defects, where the in-plane loss of constraint is basically caused by tensile loads and crack shallowness. As an example, FITNET FFS Procedure [1823] provides a complete comprehensive methodology for the assessment of low constraint conditions in cracked components, based on the T-stress or the Q parameter [32] (section 6.4.3 of the procedure), and includes guidance for the analysis of notch-type defects in a separate section (section 12). Furthermore, the procedure, based on [35], proposes that the loss of constraint caused by the notch effect is independent of that caused by tensile loads and defect shallowness $[34,37,38]$.

Another type of local approaches which are worth mentioning are those based on the Cohesive Zone Model $[39,40]$, whose application to the analysis of notches has provided noticeable contributions in the last years (e.g., [41-44]). The cohesive zone model is able to predict not only the behaviour of cracked structures, but also the behaviour of uncracked structures, including those containing blunt notches. It has successfully been applied, for example, to concrete and cementitious composites, glassy polymers such as PMMA, and some steels [40]. Here, it is important to notice that the Cohesive Zone Model defines a characteristic length $\left(1_{\mathrm{ch}}\right)$ whose expression is similar to equation (2) [40-43].

In any case, the resistant behaviour of structural components containing notches can be analysed through two different parameters: the above mentioned load bearing capacity and, when dealing with fracture assessments, the apparent fracture toughness $\left(\mathrm{K}^{\mathrm{N}}{ }_{\text {mat }}\right)($ e.g., $[15,17,18,45]$, which is that one obtained by the application of the cracked specimen formulation [24] to notched specimens. Also of great interest is the relation between the macroscopic resistant observations (i.e., load bearing capacity and apparent fracture toughness) and the fracture micromechanisms, as previously reported in $[17,18]$.

This paper focusses the analysis of notch effect on a particularly significant group of materials: ferritic-pearlitic steels, which constitute the core part of structural steels. The fracture resistance of these materials in cracked conditions presents a clear dependence on the working temperature, with brittle behaviour at low temperatures (Lower Shelf), ductile behaviour at high temperatures (Upper Shelf), and transition behaviour between the Lower Shelf and the Upper Shelf (ductile-to-brittle transition zone) $[\underline{24}, \underline{46}, \underline{47}]$, as shown in Figure 1. To the knowledge of the authors, the analysis of this temperature dependence has not been previously reported in the literature when dealing with notched conditions.

With all this, the present paper presents a description of the two steels analysed (Section 2), together with the corresponding experimental program and its results (Section 3), and the analysis of the notch effect in both the load bearing capacity and the apparent fracture toughness (Section 4). Finally, Section 5 outlines the relation between fracture micromechanisms and macroscopic resistant observations, and Section 6 gathers the final conclusions.

\section{MATERIALS}


The research reported in this paper is performed on two ferritic-pearlitic steels with, in principle, rather different fracture behaviour: steel S275JR, with a minimum specified Charpy energy of $27 \mathrm{~J}$ at $+20^{\circ} \mathrm{C}$, and $\mathrm{S} 355 \mathrm{~J} 2$, which guarantees the same Charpy energy at $-20^{\circ} \mathrm{C}$.

This section presents the basic characterisation of these two materials, comprising chemical, microstructural and tensile analyses. Table 1 gathers the chemical analysis performed by means of chemical emission spectroscopy. The results obtained satisfy the specifications of both materials.

Figure 2 shows the ferritic-pearlitic microstructures. It can be observed that the pearlitic grains are distributed more homogeneously in steel S275JR than in steel S355J2, which clearly presents alternated bands of pearlitic and ferritic nature. Moreover, the average grain size is rather different in the two steels. The corresponding grain size was determined following [48], providing values of $19.4 \mu \mathrm{m}$ and $8.3 \mu \mathrm{m}$ for steels S275JR and S355J2, respectively.

Finally, Table 2 gathers the tensile properties of the two materials at the different temperatures. They are subsequently tested within their corresponding experimental programme (see Section

$3)$, and also at room temperature $\left(+20^{\circ} \mathrm{C}\right)$. The tests were performed following [49], two at each combination of material and temperature. It can be observed how, in the two steels analysed, the lower the temperature, the higher the yield stress, the ultimate tensile strength and the Young's modulus (this effect is also accompanied by a reduction in ductility parameters). Also, both steels satisfy their specifications at room temperature.

\section{EXPERIMENTAL PROGRAM AND RESULTS}

In order to analyse the notch effect along the different zones of the material fracture behaviour (lower shelf, ductile-to-brittle transition zone and upper shelf), an experimental program composed of $336 \mathrm{CT}$ specimens has been performed. 180 of the specimens correspond to steel S275JR, and 156 correspond to steel S355J2. This difference is justified by the fact that in the latter case, it was only technically possible to perform tests at just one temperature $\left(-196^{\circ} \mathrm{C}\right)$ within the material lower shelf.

For each combination of material and test temperature, specimens containing six different types of notch radii were tested: $0 \mathrm{~mm}$ (crack-like defects), $0.15 \mathrm{~mm}, 0.25 \mathrm{~mm}, 0.50 \mathrm{~mm}, 1.0 \mathrm{~mm}$ and $2.0 \mathrm{~mm}$, as shown in Figure 3.

The experimental program started, for each material, with 6 fracture tests on CT cracked specimens at temperatures that were initially assumed to be at the material's ductile-to-brittle transition zone (DBTZ). These temperatures were $-10^{\circ} \mathrm{C}$ in the case of steel S275JR and $-100^{\circ} \mathrm{C}$ in the case of steel S355J2. After these tests, and provided the previous temperatures belonged to the higher part of the DBTZ, additional fracture tests were performed on each material at lower temperatures (still within the DBTZ): four tests at $-30^{\circ} \mathrm{C}$ and $-50^{\circ} \mathrm{C}$ in the case of steel S275JR, and four tests at $-120^{\circ} \mathrm{C}$ and $-150{ }^{\circ} \mathrm{C}$ in the case of steel $\mathrm{S} 355 \mathrm{~J} 2$. All this provided fourteen tests on each material for the determination of the reference temperature, $\mathrm{T}_{0}$, which is that which corresponds to a median fracture toughness $\mathrm{K}_{\mathrm{Jc}}$ of $100 \mathrm{MPam}^{1 / 2}$ obtained in $25 \mathrm{~mm}$ thick specimens. Applying [50], and following the multi-temperature option, a reference temperature of $-26^{\circ} \mathrm{C}$ for steel S275JR and $-133^{\circ} \mathrm{C}$ for steel S355J2 was obtained. These results 
confirm that the above mentioned testing temperatures belong to the validity range of the DBTZ defined in [50].

Now, assuming that the DBTZ is defined by $\mathrm{T}_{0}$ and, thus, modelled by the Master Curve [ $\underline{50}$, for each material two temperatures were defined belonging to the upper shelf (US), three temperatures belonging to the DBTZ, and (tentatively) two temperatures belonging to the lower shelf (LS). The temperatures at the US were those higher than $\mathrm{T}_{0}+50^{\circ} \mathrm{C}$ [50], those corresponding to the DBTZ were located within $\mathrm{T}_{0} \pm 50^{\circ} \mathrm{C}$, and $\mathrm{LS}$ temperatures were considered to be those lower than $\mathrm{T}_{0}-50^{\circ} \mathrm{C}$. All this led to testing temperatures of $+70,+40,-10,-30,-50,-$ 90 and $-120{ }^{\circ} \mathrm{C}$ for steel S275JR, and $-20,-50,-100,-120,-150$ and $-196{ }^{\circ} \mathrm{C}$ for steel S355J 2 . The temperatures located between $-50{ }^{\circ} \mathrm{C}$ and $+70{ }^{\circ} \mathrm{C}$ were obtained using an environmental chamber; temperatures below $-50^{\circ} \mathrm{C}$ required a combination of an environmental chamber and liquid nitrogen.

Tables 3 and 4 gather the complete experimental program, with the material, the geometry, the testing temperature and the results of every single tested CT specimen. It can be seen that 10 of the tests do not have any result, since the experimental procedure was not valid in those cases. The experimental results are given in terms of the load bearing capacity (LBC) and the apparent fracture toughness $\left(\mathrm{K}^{\mathrm{N}}{ }_{\text {mat }}\right)$. Concerning this latter parameter it should be noted that its value in each individual test has been obtained following the procedure specified in [24] for the determination of $\mathrm{K}_{\mathrm{Jc}}$ in cracked specimens:

$$
K_{m a t}^{N}=\sqrt{J_{m a t}^{N} \frac{E}{1-v^{2}}}
$$

where $\mathbf{J}^{\mathrm{N}}{ }_{\text {mat }}$ is the apparent $\mathrm{J}$-integral at onset of cleavage fracture, $\mathrm{E}$ is the Young's modulus and $v$ is the Poisson's ratio [22]:

$$
J_{\text {mat }}^{N}=J_{e}^{N}+J_{p}^{N}=\frac{\left(1-v^{2}\right)\left(K_{e}^{N}\right)^{2}}{E}+\frac{\eta A_{p}}{B b_{0}}
$$

where $\mathrm{J}^{\mathrm{N}}$ and $\mathrm{J}^{\mathrm{N}}$ p are, respectively, the elastic and plastic components of $\mathrm{J}^{\mathrm{N}}$ mat, $\eta$ is a dimensionless constant, $A_{p}$ is the plastic area under the load-displacement curve, $b_{0}$ is the initial remaining ligament and $\mathrm{K}_{\mathrm{e}}^{\mathrm{N}}$ is the apparent elastic stress intensity factor at instability [24]:

$$
K_{e}^{N}=\left(\frac{P}{B \cdot W^{0.5}}\right) \frac{2+\frac{a}{W}}{\left(1-\frac{a}{W}\right)^{3 / 2}} \cdot\left(0.886+4.64\left(\frac{a}{W}\right)-13.32\left(\frac{a}{W}\right)^{2}+14.72\left(\frac{a}{W}\right)^{3}-5.60\left(\frac{a}{W}\right)^{4}\right)
$$

In the particular case of cracked specimens $\mathrm{K}^{\mathrm{N}}$ mat coincides with $\mathrm{K}_{\text {mat }}$, a general term that represents the material fracture resistance in cracked conditions expressed in units of stress intensity factor. With all this, considering the results obtained in the experimental program, $\mathrm{K}^{\mathrm{N}}{ }_{\text {mat }}$ may represent the following parameters:

- $\quad \mathrm{K}_{\mathrm{Jc}}^{\mathrm{N}}$, which is the apparent fracture toughness at fracture instability prior to the onset of significant stable tearing defect extension [24]. This measure is independent of in-plane dimensions but may depend on thickness. In the case of cracks, $\mathrm{K}_{\mathrm{Jc}}^{\mathrm{N}}$ coincides with $\mathrm{K}_{\mathrm{Jc}}$. 
This is the most common case and corresponds to tests where the load-displacement curve present is similar to those shown in Figure 4a.

- $\mathrm{K}_{\mathrm{Ju}}^{\mathrm{N}}$, which is the apparent fracture toughness at fracture instability after the onset of significant stable tearing defect extension. This measure may be size-dependent and a function of test specimen geometry. This is the case when the combination of a relatively high temperature (higher part of ductile-to-brittle transition zone and upper shelf) and notch radius allows the defect to develop important amounts of tearing before final fracture, and the load-displacement curves are similar to those shown in Figure 4b.

- $\mathrm{K}_{\mathrm{Jt}}^{\mathrm{N}}$, which is the apparent fracture toughness measured in those specimens where there is no instability, but a ductile tearing along the whole resistant section. This parameter has a clear dependence on the geometry and the load displacement-curves are similar to that shown in Figure 4c, and corresponds to some of the tests performed on notched specimens operating at upper shelf temperatures.

Although $\mathrm{K}_{\mathrm{Jc}}^{\mathrm{N}}, \mathrm{K}_{\mathrm{Ju}}^{\mathrm{N}}$ and $\mathrm{K}_{\mathrm{Jt}}^{\mathrm{N}}$ depend (to a different extent) on the geometry of the specimens, this geometry is kept constant here (except for the notch radius), so for the purpose of notch effect analysis this question is not an issue.

\section{ANALYSIS OF NOTCH EFFECT}

\subsection{Notch effect on load bearing capacity}

The results shown in tables 3 and 4 reveal a clear increase in the LBC with notch radius, especially for lower shelf (LS) conditions. In both materials most of this increase takes place when introducing the first notch radius (i.e., $0.15 \mathrm{~mm}$ ), after which the increase is much more moderate. Also, steel S355J2 presents greater differences between the material LBC at the LS and the LBC at the other temperature regions (DBTZ and US). In order to better analyse the notch effect on LBC, figures 5 to 7 present the results for each material and temperature condition, with the LBC being normalised by the average load bearing capacity in cracked conditions $\left(\mathrm{LBC}_{0}\right)$.

Figure 5, which presents the results at the corresponding LS, shows how the LBC for a notch radius of $2.0 \mathrm{~mm}$ is approximately 2.3 times higher in steel S275JR (considering average values), and 4.1 in steel S355J2, than the LBC in cracked conditions. In the first case, most of the increase in LBC takes place when the first notch radius is introduced in the material, whereas in S355J2 the increase takes place along the whole range of the notch radii (although it is also decelerated).

Figure 6 shows the results at the DBTZ of the two materials analysed. It can be observed how the higher the temperature the lower the notch effect: the factor by which the LBC in cracked conditions is multiplied when introducing a notch radius of $2.0 \mathrm{~mm}$ is, respectively, 2.5, 2.2 and 1.9 for $-50^{\circ} \mathrm{C},-30^{\circ} \mathrm{C}$ and $-10^{\circ} \mathrm{C}$ in steel S275JR, and 3.1, 1.6 and 1.6 for $-150^{\circ} \mathrm{C},-120^{\circ} \mathrm{C}$ and $100^{\circ} \mathrm{C}$ in steel S355J2.

Figure 7 presents the results obtained in the upper shelf of the two materials. In this case the notch effect is very limited: although there is an increase in the LBC with notch radius, the LBC of specimens containing a notch radius of $2.0 \mathrm{~mm}$ is 1.1 times higher than that obtained in cracked specimens, for steel S275JR at both $40^{\circ} \mathrm{C}$ and $70^{\circ} \mathrm{C}$, and 1.3 times higher for steel 
$\mathrm{S} 355 \mathrm{~J} 2$ at $-50^{\circ} \mathrm{C}$ and $-20^{\circ} \mathrm{C}$. It can also be observed that once the material is operating at temperatures within the US, the notch effect is stabilised.

With all this, it can be concluded that the notch effect is progressively lower when increasing the temperature. At LS temperatures, this effect has its maximum, the minimum values appearing at the US. Figure 8 gathers this effect, in which it can be observed how there is a transitional behaviour along the corresponding DBTZ. The figure represents the relation between the average $\mathrm{LBC}$ obtained in specimens with a $2.0 \mathrm{~mm}$ notch radius, and the average LBC obtained in cracked specimens.

Finally, it is also interesting to analyse how the temperature affects the material behaviour for a particular notch radius. Figure 9 shows the evolution of the LBC for defects with notch radii of $0 \mathrm{~mm}, 0.5 \mathrm{~mm}$ and $2.0 \mathrm{~mm}$. It can be observed how the higher the notch radii the lower the temperature effect: the two materials present a clear temperature effect in cracked conditions (as expected due to their ferritic-pearlitic nature $[24,46,47])$, but this effect is much more limited (even negligible in steel S275JR) for notch radii of $0.5 \mathrm{~mm}$ and $2.0 \mathrm{~mm}$.

\subsection{Notch effect on apparent fracture toughness}

Analogously to the analysis performed concerning the LBC, tables 3 and 4 reveal an increase in $\mathrm{K}^{\mathrm{N}}$ mat with notch radius, although this increase is much more limited in US conditions. Also, contrary to the LBC observations, the increase in $\mathrm{K}^{\mathrm{N}}$ mat does not mostly take place when introducing the first notch radius (i.e., $0.15 \mathrm{~mm}$ ), but rather takes place more continuously all along the range of notch radii considered in the analysis. In order to better analyse the notch effect on $\mathrm{K}^{\mathrm{N}}$ mat, figures 10 to 12 present the results for each material and temperature condition, with the $\mathrm{K}^{\mathrm{N}}$ mat being normalised by the average fracture toughness in cracked conditions $\left(\mathrm{K}_{\mathrm{mat}}\right)$.

Figure 10 presents the results at the corresponding LS. It can be observed that, when considering average values, the $\mathrm{K}^{\mathrm{N}}$ mat obtained with notch radius of $2.0 \mathrm{~mm}$ is approximately 7.0 times higher than the $\mathrm{K}_{\text {mat }}$ in steel S275JR at $-120^{\circ} \mathrm{C}$, and 9.6 times at $-90^{\circ} \mathrm{C}$, with peak values of 11.8 and 13.2 , respectively. In the case of steel $355 \mathrm{~J} 2$ at $-196^{\circ} \mathrm{C}$, the average value of $\mathrm{K}^{\mathrm{N}}$ mat with notch radius of $2.0 \mathrm{~mm}$ is 4.0 times higher than the corresponding average value of $\mathrm{K}_{\text {mat }}$, presenting a maximum of 4.5. Therefore, the notch effect in the apparent fracture toughness is much more pronounced in steel S275JR than in steel S355J2, contrarily to what happened with the notch effect in the LBC. Also, although in steel S355J2 the notch effect is similar in both parameters $\left(\mathrm{K}^{\mathrm{N}}\right.$ mat and LBC), in the case of steel S275JR this effect is noticeably higher on the $\mathrm{K}^{\mathrm{N}}$ mat. In the two materials, the increase in $\mathrm{K}^{\mathrm{N}}$ mat takes place all along the range of notch radii considered here.

Figure 11 shows the results at the DBTZ of the two materials being analysed. As observed with the LBC, the higher the temperature the lower the notch effect, although for the two materials the notch effect at the DBTZ is generally higher than the notch effect in the lower shelf. Also, in most cases the factor by which the $\mathrm{K}^{\mathrm{N}}{ }_{\text {mat }}$ in cracked conditions $\left(\mathrm{K}_{\mathrm{mat}}\right)$ is multiplied when introducing a notch radius of $2.0 \mathrm{~mm}$ is higher that the factor obtained above for LBC measurements.

Figure 12 gathers the results obtained in the upper shelf of the two materials. Again, as observed with the LBC, the notch effect is much more limited than that observed at lower temperatures, 
but in this case this effect is still noticeable and more significant that that observed with the LBC: in the case of steel S275JR the $\mathrm{K}^{\mathrm{N}}$ mat of specimens containing a notch radius of $2.0 \mathrm{~mm}$ is 1.9 (at $40^{\circ} \mathrm{C}$ ) and 1.4 (at $70^{\circ} \mathrm{C}$ ) times higher than that obtained in cracked specimens, whereas in the case of steel $\mathrm{S} 355 \mathrm{~J} 2$ this factor is 2.7 and 1.6 at $-50^{\circ} \mathrm{C}$ and $-20^{\circ} \mathrm{C}$ respectively. Therefore, contrarily to the observations in the $\mathrm{LBC}$, the $\mathrm{K}^{\mathrm{N}}$ mat measurements obtained here are not constant along the material upper shelf.

Therefore, with all this, it can be concluded that the notch effect in the $\mathrm{K}^{\mathrm{N}}$ mat is generally higher than the notch effect in the LBC. Also, the effect on $\mathrm{K}^{\mathrm{N}}$ mat, in contrast with the observations of the LBC, presents a maximum at the lower temperatures of the DBTZ, with a progressive decrease towards higher temperatures but also with higher values than those observed at the lower shelf. Figure 13 gathers this behaviour representing the relation between the average apparent fracture toughness obtained in specimens with a $2.0 \mathrm{~mm}$ notch radius, and the average fracture toughness measured in cracked specimens.

Finally, Figure 14 analyses how the temperature affects the $\mathrm{K}^{\mathrm{N}}$ mat for a particular notch radius. This figure shows the evolution of the $\mathrm{K}^{\mathrm{N}}$ mat for defects with notch radii of $0 \mathrm{~mm}, 0.5 \mathrm{~mm}$ and $2.0 \mathrm{~mm}$. It can be observed how the higher the notch radii the lower the temperature effect: the two materials present a clear temperature effect in cracked conditions, this effect being more moderate for notch radii of $0.5 \mathrm{~mm}$ and $2.0 \mathrm{~mm}$. In any case, by comparison of figures 9 and 14 , the notch effect at higher radii is more evident when it is measured through the $\mathrm{K}^{\mathrm{N}}$ mat than when it is measured through the LBC.

\section{ANALYSIS OF FRACTURE MICROMECHANISMS}

Once the experimental results of the 336 specimens, in terms of both the $\mathrm{LBC}$ and the $\mathrm{K}^{\mathrm{N}}$ mat, have been presented, described and analysed, this section gathers the analysis of the fracture micromechanisms, performed using Scanning Electron Microscopy (SEM). The authors have previously reported $[\underline{17}, \underline{18]}$ that, beyond the stress relaxation generated by the presence of a finite notch, the notch effect also generates an evolution of fracture micromechanisms. Thus, for a given material and condition, and assuming brittle behaviour in cracked conditions, the fracture micromechanisms become more and more non-linear (ductile) when the notch radius

increases, something that may be related to the corresponding progressive loss of constraint-

Therefore, the intention here is to confirm this tendency in fracture micromechanisms and to explain some of the experimental observations, such as the reason why the two analysed materials present different intensities of the notch effect or why this effect is higher at low temperatures belonging to the DBTZ than at lower shelf temperatures.

\subsection{Fracture micromechanisms in the lower shelf}

Figures 15 and 16 show the fracture micromechanisms observed in specimens with notch radii of $0 \mathrm{~mm}$ (crack-type defect), $0.5 \mathrm{~mm}$ and $2.0 \mathrm{~mm}$. Figure 15 corresponds to steel S275JR at $120^{\circ} \mathrm{C}$ and $-90^{\circ} \mathrm{C}$ and Figure 16 gathers the observations on steel S355J2. In the three cases, the specimens included in these figures correspond to those providing intermediate results of $\mathrm{K}^{\mathrm{N}}{ }_{\text {mat }}$.

In the first case (Figure 15), it can be observed that the fracture micromechanisms are essentially the same for the three notch radii analysed at $-120{ }^{\circ} \mathrm{C}$, with a brittle aspect of the 
fracture surface and cleavages as the fracture micromechanism. Consequently, the introduction of notches of increasing radius is not accompanied by an evolution of the fracture mechanisms, and the notch effect can only be ascribed to the stress relaxation caused by the introduction of a finite notch radius.

In the case of steel S275JR at $-90{ }^{\circ} \mathrm{C}$ (Figure 20d to 20f), it can be observed that the fracture micromechanisms are predominantly brittle for the three radii included in the analysis, but in the case of specimens with notch radii of $0.5 \mathrm{~mm}$ and $2.0 \mathrm{~mm}$ there are small areas along the initial defect front containing non-linear mechanisms, these areas being larger for the $2.0 \mathrm{~mm}$ notch radius. This is in agreement with the observations made in $[17,18]$, and the notch effect here includes two different contributions: the stress relaxation at the defect tip, and the evolution in fracture micromechanisms that may be caused by a progressive reduction of the constraint conditions at the notch tip when the notch radius increases. This-These may be the reasons why a higher notch effect has been observed at $-90^{\circ} \mathrm{C}$ than at $-120^{\circ} \mathrm{C}$.

Finally, in Figure 16, (steel S355J2 at $-196^{\circ} \mathrm{C}$ ), it can be observed that there is no change in fracture micromechanisms, with a brittle aspect of the fracture surface and a lack of non-linear processes in the three radii analysed. Thus, the notch effect, which is the lowest one in the three situations here analysed, is caused only by the stress relaxation at the defect tip.

The SEM observations have also explained the high scatter observed in certain situations, especially concerning $\mathrm{K}^{\mathrm{N}}$ mat in S275JR specimens with a $2.0 \mathrm{~mm}$ notch radius. Figure 17 shows the fracture micromechanisms in two of the steel S275JR specimens: the first one, specimen 2.45 , corresponds to the lowest obtained value of $\mathrm{K}^{\mathrm{N}}$ mat; the second one (specimen 2.48) corresponds to the highest $\mathrm{K}^{\mathrm{N}}$ mat. It can be observed how, in the first case, fracture micromechanisms are basically brittle, the notch effect being uniquely caused by the stress relaxation. However, in the second case, there are a significant number of non-linear mechanisms, which generate an additional notch effect to that caused by the stress relaxation and, consequently, a much higher $\mathrm{K}^{\mathrm{N}}$ mat.

\subsection{Fracture micromechanisms in the ductile-to-brittle transition zone}

As shown above, six different combinations of material and temperature have been analysed within the ductile-to-brittle transition zone. For the sake of simplicity, just three of them are shown here. Figures 18a to $18 \mathrm{c}$ present the evolution of the fracture micromechanisms in steel $\mathrm{S} 275 \mathrm{JR}$ at $-50^{\circ} \mathrm{C}$, that is, at temperatures belonging to the ductile-to-brittle transition zone and located below the corresponding reference temperature $\left(\mathrm{T}_{0}\right)$. It can be observed that the cracked specimen has a brittle aspect with a direct transition from the precracking surface to the final fracture surface, where multiple cleavages can be observed. There is a very narrow whitish line along the initial crack front, in the middle of Figure 18a, that may be an indication of non-linear processes, but it is of very limited thickness (around $10 \mu \mathrm{m}$ ). This constitutes a first difference if compared to the observations made in the lower shelf.

Once a finite notch radius is introduced in the specimen, non-linear processes clearly appear. Figure 18b shows an image of S275JR specimen 2-53, corresponding to a notch radius of 0.15 $\mathrm{mm}$. It can be seen how there is an initiation area after the initial crack that does not correspond to cleavage fracture (it presents microvoids). Finally, after the initiation area, brittle fracture dominates again. 
Lastly, the size of the initiation areas generally grows with the notch radius, something that has a direct effect on both the LBC and, specially, the $\mathrm{K}^{\mathrm{N}}{ }_{\text {mat }}$ results.

Figures $18 \mathrm{~d}$ to $18 \mathrm{f}$ gather the evolution of the fracture micromechanisms in steel S355J2 at $150^{\circ} \mathrm{C}$, again, a temperature belonging to the ductile-to-brittle transition zone and located below the corresponding reference temperature. Here, although there is a clear evolution of fracture micromechanisms when observing the whole sequence of fractographies, there is no direct link between them and the $\mathrm{LBC}$ and $\mathrm{K}^{\mathrm{N}}$ mat measurements: the latter increases significantly for very small notch radii (e.g., $0.15 \mathrm{~mm}$ and 0.25 ), but the change in fracture micromechanisms appears for larger radii $(1.0 \mathrm{~mm})$. Thus, the increase in the macroscopic measurements takes place, firstly, driven by the stress relaxation, and afterwards, by the combination of the stress relaxation and the change in the fracture micromechanisms. In any case, this evolution of fracture micromechanisms is totally different to the observations made at $-196^{\circ} \mathrm{C}$, where these micromechanisms remained brittle along the whole range of the notch radii.

The observations gathered in Figure 18 show why the maximum notch effect on the apparent fracture toughness takes place at low temperatures within the DBTZ: while the notch effect is basically caused by the stress relaxation at temperatures belonging to the lower shelf, this stress relaxation is accompanied by a clear evolution in the fracture micromechanisms at lower temperatures of the DBTZ. These two coupled effects generate the maximum observed notch effect in this research.

Analogously to the observations in Figure 17, the SEM analysis has also explained the scatter observed in the results. As an example, the fracture surfaces of steel S355J2 specimen 3-45 (maximum $\mathrm{K}^{\mathrm{N}}$ mat value) presented a continuous initiation area containing ductile mechanisms, whereas specimen 3-48 (minimum $\mathrm{K}^{\mathrm{N}}$ mat value) presented cleavages as the dominant fracture mechanism. These different fracture observations have led to substantial differences in the LBC and vast (higher than $300 \%$ ) differences in $\mathrm{K}^{\mathrm{N}}$ mat.

Finally, the SEM observations made at higher temperatures within the DBTZ of the two materials analysed present a clear tendency: the higher the temperature the larger the non-linear processes for each notch radius. Figure 19 shows, as an example, the observations made in steel $\mathrm{S} 275 \mathrm{JR}$ at $-10^{\circ} \mathrm{C}$. It can be seen that there are non-linear processes even in cracked conditions, so the differences in fracture micromechanisms are not as significant as those observed at lower temperatures. This, in the end, generates a lower notch effect.

\subsection{Fracture micromechanisms in the upper shelf}

The SEM observations in the upper shelf have revealed large numbers of ductile processes in the two materials even in cracked conditions. Although the size of the areas containing nonlinear mechanisms grows with the notch radius, the fracture mechanisms are basically the same. This generates the low notch effect on both the LBC and the $\mathrm{K}^{\mathrm{N}}$ mat analysed in Section 4. Figure 20 shows the observations made in steel S275JR specimens tested at $40^{\circ} \mathrm{C}$.

Moreover, for a given notch radius, there have not been significant changes in the fracture micromechanisms. This explains the low scatter observed in the upper shelf conditions. 


\section{CONCLUSIONS}

This paper presents the analysis of notch effect in two ferritic-pearlitic steels, S275JR and S355J2. This notch effect is analysed at temperatures varying from the corresponding lower shelf up to the upper shelf, covering the different types of material fracture behaviour. The experimental program is composed of $336 \mathrm{CT}$ fracture specimens with notch radii varying from $0 \mathrm{~mm}$ up to $2.0 \mathrm{~mm}$.

The notch effect has been analysed by means of two different parameters: the load bearing capacity (LBC) and the apparent fracture toughness $\left(\mathrm{K}^{\mathrm{N}}{ }_{\text {mat }}\right)$. The main conclusions obtained are the following:

- A notch effect has been observed a in both materials, such that both the LBC and the $\mathrm{K}^{\mathrm{N}}$ mat are higher when the notch radius increases. This has been observed at the different regions of material fracture behaviour.

- The notch effect in the LBC has its maximum at lower shelf (LS) temperatures, the minimum values appearing at the upper shelf (US).

- It has also been observed that the higher the notch radii the lower the temperature effect on the LBC.

- The notch effect in the $\mathrm{K}^{\mathrm{N}}$ mat is generally higher than the notch effect in the LBC. Also, the effect on $\mathrm{K}^{\mathrm{N}}{ }_{\text {mat }}$, in contrast with the observations of the $\mathrm{LBC}$, presents a maximum at the lower temperatures of the DBTZ.

- Similarly to the observations on the LBC, it has also been observed that the higher the notch radii the lower the temperature effect in $\mathrm{K}^{\mathrm{N}}$ mat, although this effect is more evident when it is measured through the $\mathrm{K}^{\mathrm{N}}$ mat than when it is measured through the LBC.

- The SEM fractographies have justified the above observations. A general trend has been observed that consists in the change in fracture micromechanisms when the notch radius and/or the temperature increases. The maximum notch effect on $\mathrm{K}^{\mathrm{N}}$ mat takes place at low temperatures of the ductile-to-brittle transition zone due to the combined effect of stress relaxation and the change in fracture micromechanisms, which are brittle for cracked conditions and present non-linear micromechanisms for higher notch radii.

\section{Acknowledgements}

The authors of this work would like to express their gratitude to the Spanish Ministry of Science and Innovation for the financial support of the project MAT2010-15721: 'Análisis de integridad estructural en defectos tipo entalla', on the results of which this paper is based.

\section{REFERENCES}

[1] Timoshenko S, Goodier JN (1951) Theory of Elasticity. McGraw-Hill.

[2] Neuber N, Weiss V (1962) Trans ASME. Paper No. 62-WA-270.

[3] Creager M, Paris C (1967) Elastic field equations for blunt cracks with reference to stress corrosion cracking. Int J Fract 3:247-252.

[4] Chen CC, Pan HI (1978) In: Chen CC (ed) Collection of Papers on Fracture of Metals. Metallurgy Industry Press, Beijing, pp 197-219. 
[5] Usami SI (1985) Short crack fatigue properties and component life estimation. In: Tanaka T, Jono M, Komai K (ed) Current Research on Fatigue Cracks, The Society of Materials Science Kyoto, pp 101-125.

[6] Glinka G, Newport A (1987) Universal features of elastic notch tip stress fields. Int J Fatigue 9: 143-150.

[7] Kujawski D (1991) Estimation of Stress Intensity Factors for Small Cracks at Notches. Fatigue Fract Eng Mater Struct 14: 953-965.

[8] Niu LS, Chehimi C, Pluvinage G (1994) Stress Field Near a Large Blunted V Notch and Application of the Concept of Critical Notch Stress Intensity Factor to the Fracture of Very Brittle Materials. Eng Fract Mech 49: 325-335.

[9] Bhattacharya S, Kumar AN (1995) Rotational Factor Using Bending Moment Approach Under Elasto-plastic Situation in 3PB Notch Geometry. Eng Fract Mech 50: 495-505.

[10] Pluvinage G (1998) Fatigue and Fracture Emanating from Notch; the Use of the Notch Stress Intensity Factor. Nucl Eng Des 185: 173-184.

[11] Neuber H (1958) Theory of notch stresses: principles for exact calculation of strength with reference to structural form and material. Springer Verlag, Berlin.

[12] Peterson RE (1959) Notch sensitivity. In: Sines G, Waisman JL (ed) Metal fatigue. McGraw Hill, New York, pp 293-306.

[13] Bao Y, Jin Z (1993) Size effects and mean strength criterion for ceramics. Fatigue Fract Eng Mater Struct 16:829-835.

[14] Fenghui W (2000) Prediction of intrinsic fracture toughness for brittle materials from the apparent toughness of notched-crack specimen. J Mater Sci 35:2543-2546.

[15] Taylor D (2007) The theory of critical distances: a new perspective in fracture mechanics. Elsevier.

[16] Berto F, Lazzarin P (2009) A review of the volume-based strain energy density approach applied to V-notches and welded structures. Theor Appl Fract Mech 52:183-194

[17] Cicero S, Madrazo V, Carrascal IA (2012) Analysis of notch effect in PMMA by using the Theory of Critical Distances. Eng Fract Mech 86:56-72.

[18] Madrazo V, Cicero S, Carrascal IA (2012) On the point method and the line method notch effect predictions in A17075-T651. Eng Fract Mech 79:363-379.

[19] Berto F, Lazzarin P (2014) Recent developments in brittle and quasi-brittle failure assessment of engineering materials by means of local approaches. Mater Sci Eng R Rep 75:1$\underline{48}$

[20] R6: Assessment of the integrity of structures containing defects (2001). Revision 4. British Energy Generation Limited.

[21] BS 7910: 2005 (2005) Guide to methods for assessing the acceptability of flaws in metallic structures. British Standards Institution, London.

[22] API 579-1/ASME FFS-1 Fitness-For-Service (2007). American Society of Mechanical Engineers, New York.

[23] FITNET Fitness-for-Service (FFS) Proceure - Volume 1 (2008), M. Kocak, S. Webster, J.J. Janosch, R.A. Ainsworth, R. Koers (ed)., ISBN 978-3-940923-00-4, GKSS, Germany.

[24] ASTM E1820-09e1 (2009). Standard test method for measurement of fracture toughness. American Society for Testing and Materials, Philadelphia.

[2325] Seweryn A, Lukaszewicz A (2002) Verification of brittle fracture criteria for elements with V-shaped notches. Eng Fract Mech 69:1487-1510.

[2426] Leguillon D (2002) Strength or toughness? A criterion for crack onset at a notch. European Journal of Mechanics, A/Solids 21: 61-72. 
[2527] Leguillon D, Quesada D, Putot C, Martin E (2007) Prediction of crack initiation at blunt notches and cavities-size effects. Eng Fract Mech 74:2420-2436.

[28] Beremin F (1981) Experimental and numerical study of the different stages in ductile rupture: application to crack initiation and stable crack growth. In: Nemat-Nasser S (ed) Three dimensional constitutive relations and ductile fracture. North Holland Publishing Company, pp 185-205.

[29] Beremin F (1983) A local criterion for cleavage fracture of a nuclear pressure vessel. Metall Trans 14a: 2277-2287.

[30] Landes JD, McCabe DE, Ernst HA (1989) Geometry effects on the R-curve. In: Landes JD, Saxena A, Merkle JG (ed) Non linear fracture mechanics: Volume 2 - Elastic Plastic Fracture, ASTM STP 905. ASTM, Philadelphia, pp 123-143.

[31] Kishimoto K, Takeuchi N, Auki S., Sakata M (1990) Computational accuracy of the integral by the finite-element method. Int J Pres Ves Pip 44: 255-266.

[32] O’Dowd NP, Shih CF (1992) Family of crack tip fields characterised by a triaxiality parameter: part II- fracture applications. J Mech Phys Solids 40: 939-963.

[33] Hancock JW, Reuter WG, Parks DM (1993) Constraint and toughness parameterized by T. In: Hackett EM, Schwalbe KH, Dodds RH (ed) Constraint Effects in Fracture, ASTM STP 1171. ASTM, Philadelphia, pp. 21-40.

[34] Cicero S., Ainsworth RA, Gutiérrez-Solana F (2010) Engineering approaches for the assessment of low constraint conditions: A critical review. Eng Fract Mech 77:1360-1374.

[35] Wang X, Lewis T, Bell R (2006) Estimations of the T-stress for small cracks at notches. Eng Fract Mech 73: 366-375

[36] Hadj Meliani M, Azari Z, Pluvinage G, Matvienko YG (2010) The effective T-stress estimation and crack paths emanating from U-notches. Eng Fract Mech 77:1682-1692.

[37] Cicero S, Gutiérrez-Solana F, Álvarez JA (2008) Structural integrity assessment of components subjected to low constraint conditions. Eng Fract Mech 75:3038-3059.

[38] Gutiérrez-Solana F, Cicero S (2009) FITNET FFS procedure: A unified European procedure for structural integrity assessment. Eng Fail Anal 16: 559-577.

[39] Bazant ZP, Planas J (1998) Fracture and size effects in concrete and other quasibrittle materials. CRC Press, Florida.

[40] Elices M, Guinea GV, Gómez J, Planas J (2002) The cohesive zone model: advantages, limitations and challenges. Eng Fract Mech 69:137-163

[41] Gómez FJ, Elices M, Planas J (2005) The cohesive crack concept: application to PMMA at $-60^{\circ} \mathrm{C}$. Eng Fract Mech 78: 1268-1285

[42] Berto F, Lazzarin P, Gómez FJ, Elices M (2007) Fracture assessment of U-notches under mixed mode loading: two procedures based on the "equivalent local mode I" concept. Int J Fract 148:415-433

[43] Gómez FJ, Elices M, Berto F, Lazzarin P (2008) A generalised notch stress intensity factor for U-notched components loaded under mixed mode. Eng Fract Mech 75:4819-4833

[44] Cendón DA, Berto F, Lazzarin P, Elices M (2013) The cohesive crack model applied to notched PMMA specimens obeying a non linear behaviour under torsion loading. Key Eng Mat 577-578:49-52

[45] Ayatollahi MR, Dehghany M, Nejati M (2011) Fracture analysis of V-notched components - Effects of first non-singular stress term. Int J Sol Struct 48:1579-1589

[46] Anderson TL (1991) Fracture mechanics: fundamentals and applications. CRC Press, Florida.

[47] Wallin K (1984) The scatter in $\mathrm{K}_{\mathrm{IC}}$ results. Eng Fract Mech 19: 1085-1093. 
| [48] ASTM E112-10 (2010) Standard test methods for determining average grain size. American Society of Testing and Materials, Philadelphia.

[49] ASTM E8/E8M-09 (2009) Standard Test Methods for Tension Testing of Metallic Materials. American Society of Testing and Materials, Philadelphia.

[50] ASTM E1921-05 (2005) Standard test method for determination of reference temperature, $\mathrm{T}_{0}$, for ferritic steels in the transition range. American Society for Testing and Materials, Philadelphia. 


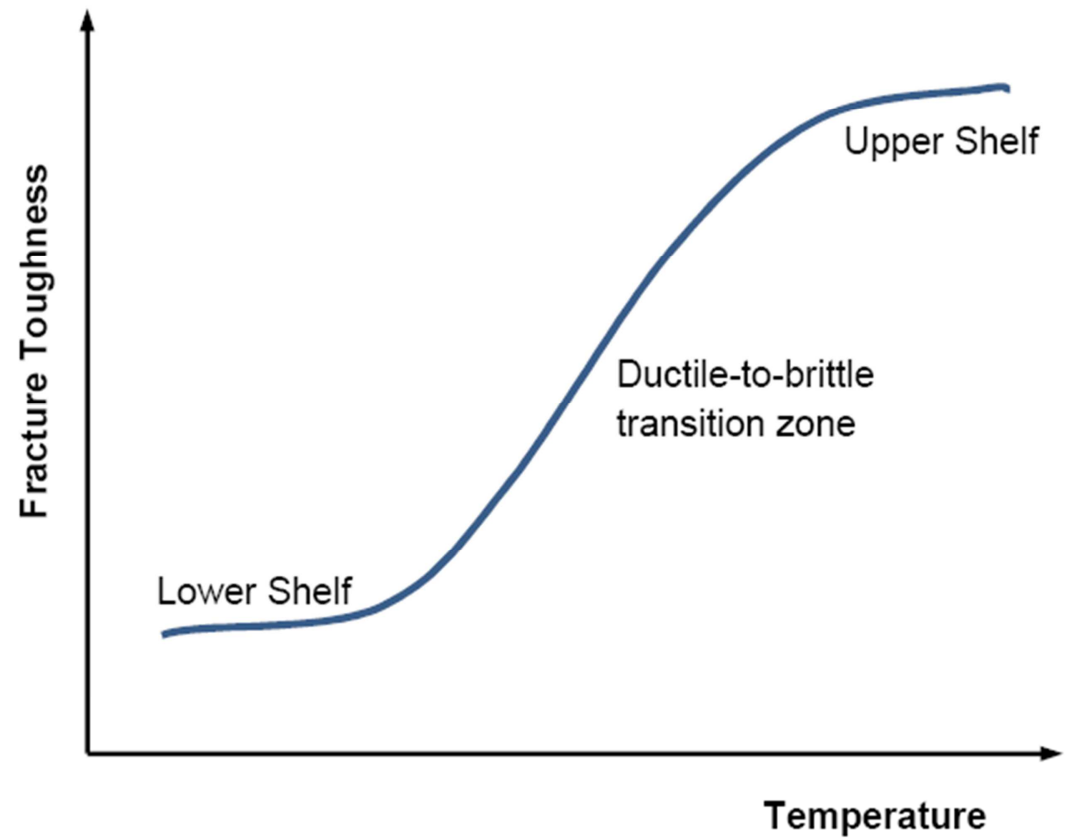

Figure 1. Schematic showing the different regions of fracture behaviour in ferritic-pearlitic steels. 


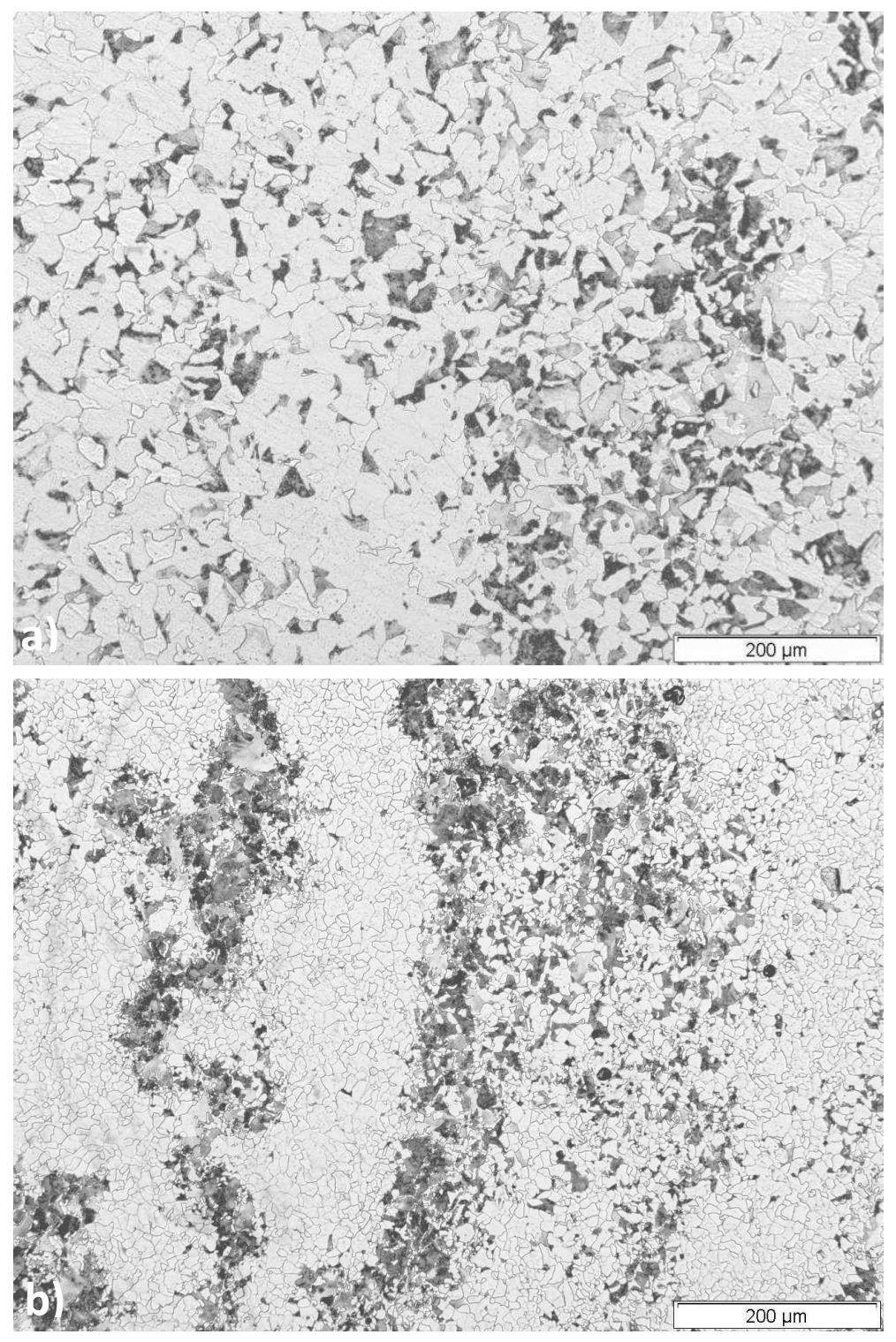

Figure 2. Microstructure of the steels being analysed: a) S275JR; b) S355J2. 


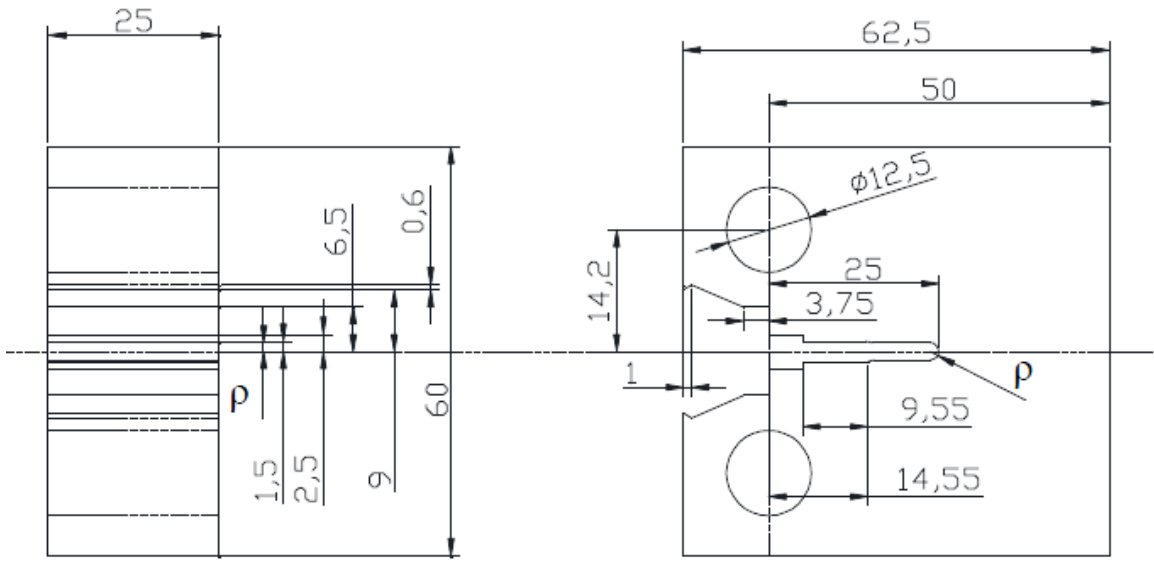

Figure 3. Schematic showing the geometry of the specimens (dimensions in $\mathrm{mm}$ ). $\rho$ varying from $0 \mathrm{~mm}$ up to $2.0 \mathrm{~mm}$. 

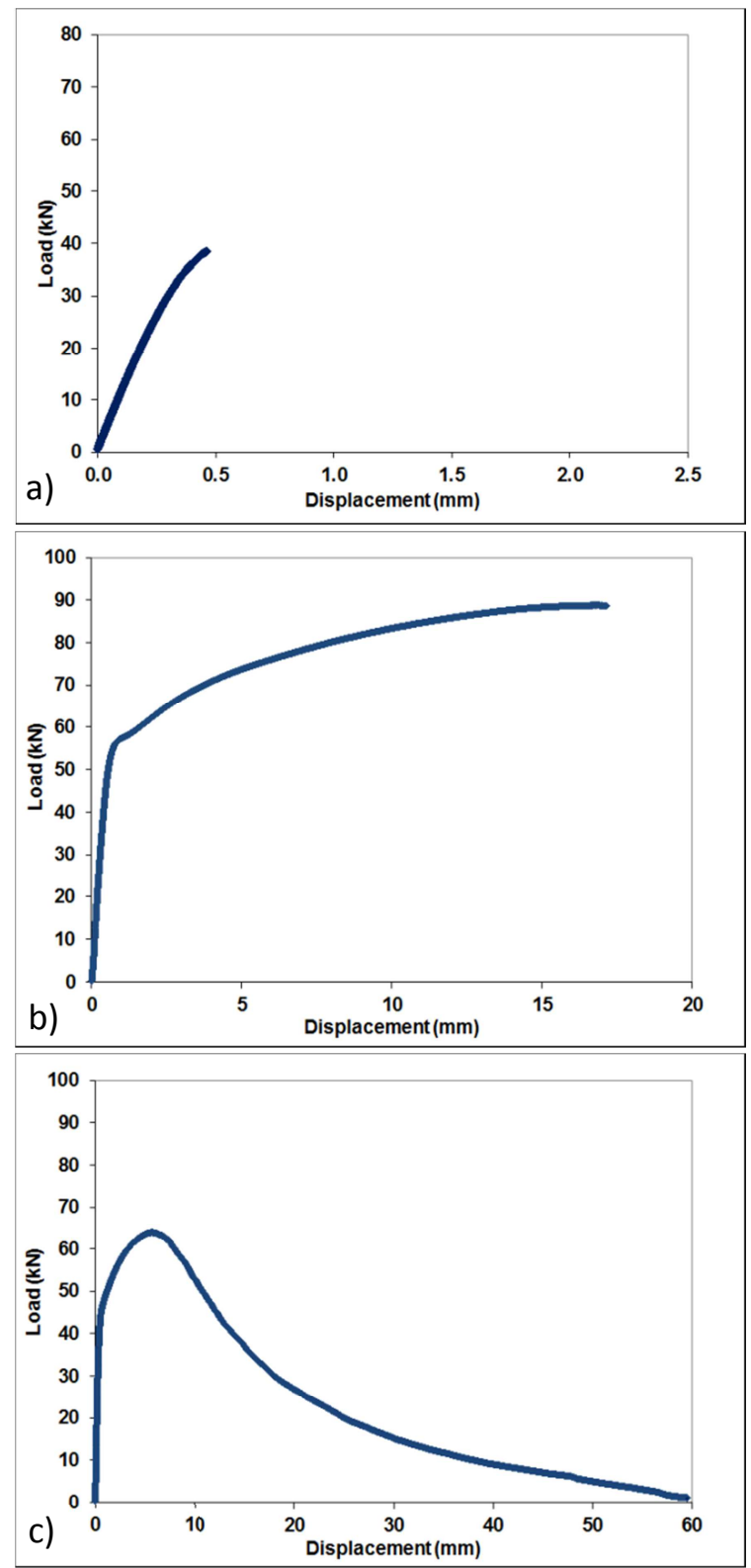

Figure 4. Load-displacement curves in two specimens providing $\mathrm{K}_{\mathrm{Jc}}^{\mathrm{N}}$ results: a) specimen 2-75 $\left.\left(\rho=0 \mathrm{~mm}, \mathrm{~T}=-30^{\circ} \mathrm{C} ; \mathrm{K}_{\mathrm{Jc}}=100.1 \mathrm{MPam}^{1 / 2}\right) ; \mathrm{b}\right)$ specimen $3-132\left(\rho=2.0 \mathrm{~mm}, \mathrm{~T}=-50^{\circ} \mathrm{C} ; \mathrm{K}_{\mathrm{Ju}}^{\mathrm{N}}=1046.5\right.$ $\left.\left.\mathrm{MPam}^{1 / 2}\right) ; \mathrm{c}\right)$ specimen $2-163\left(\rho=0.15 \mathrm{~mm}, \mathrm{~T}=70^{\circ} \mathrm{C} ; \mathrm{K}_{\mathrm{Jt}}=1052.6 \mathrm{MPam}^{1 / 2}\right)$ 


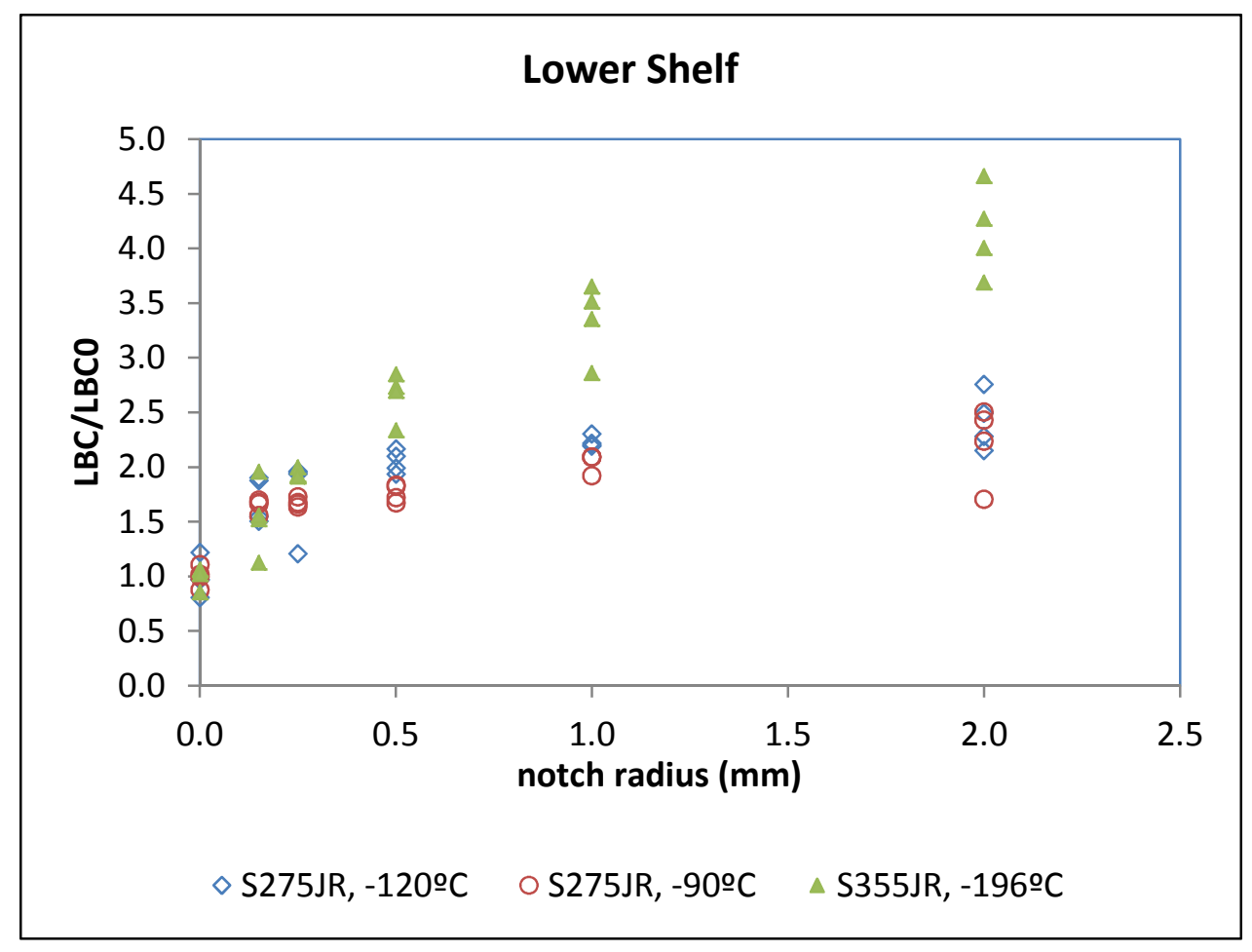

Figure 5. Load bearing capacity (LBC) results at lower shelf. 

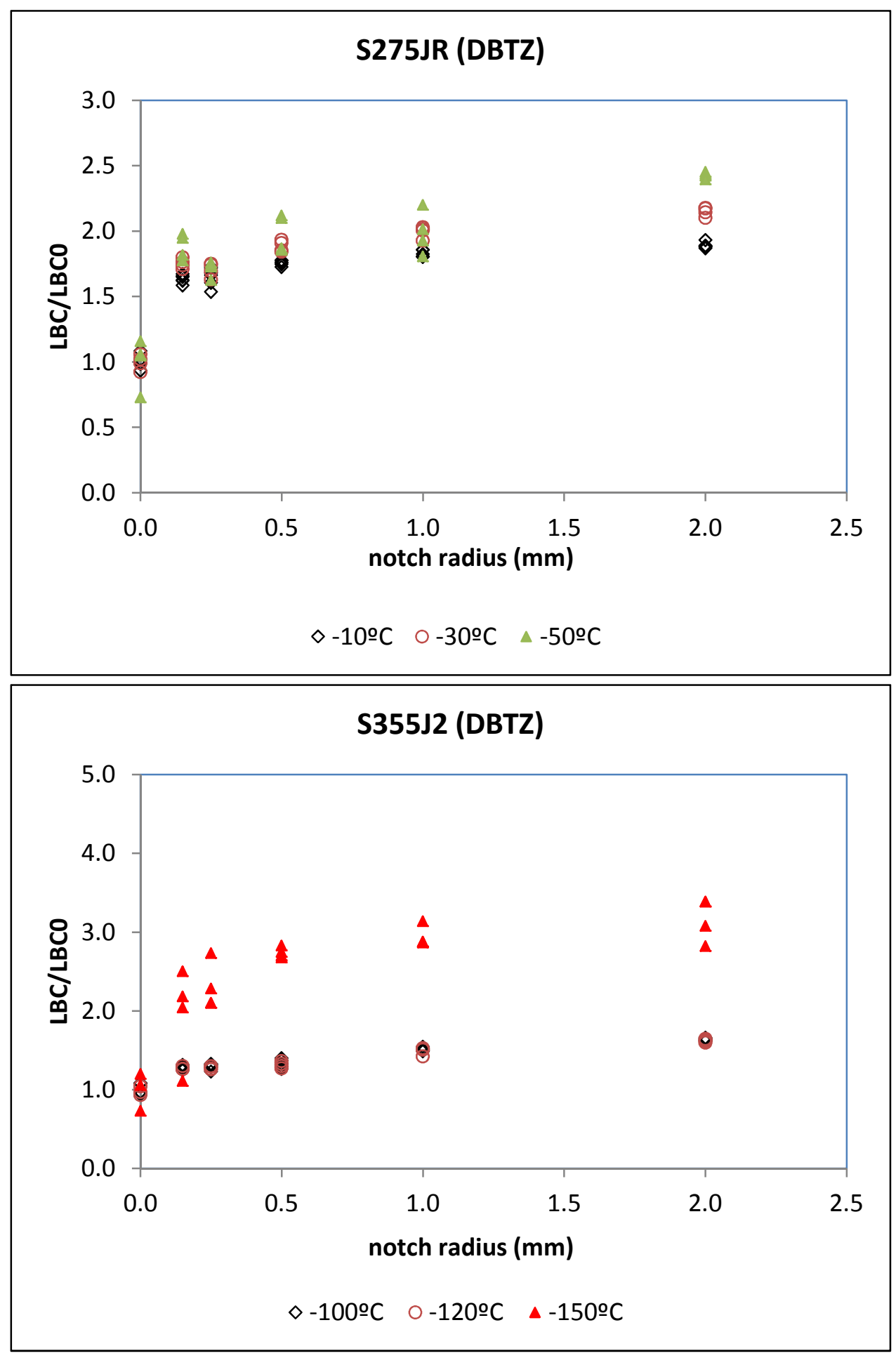

Figure 6. Load bearing capacity (LBC) results at ductile-to-brittle transition zone. 


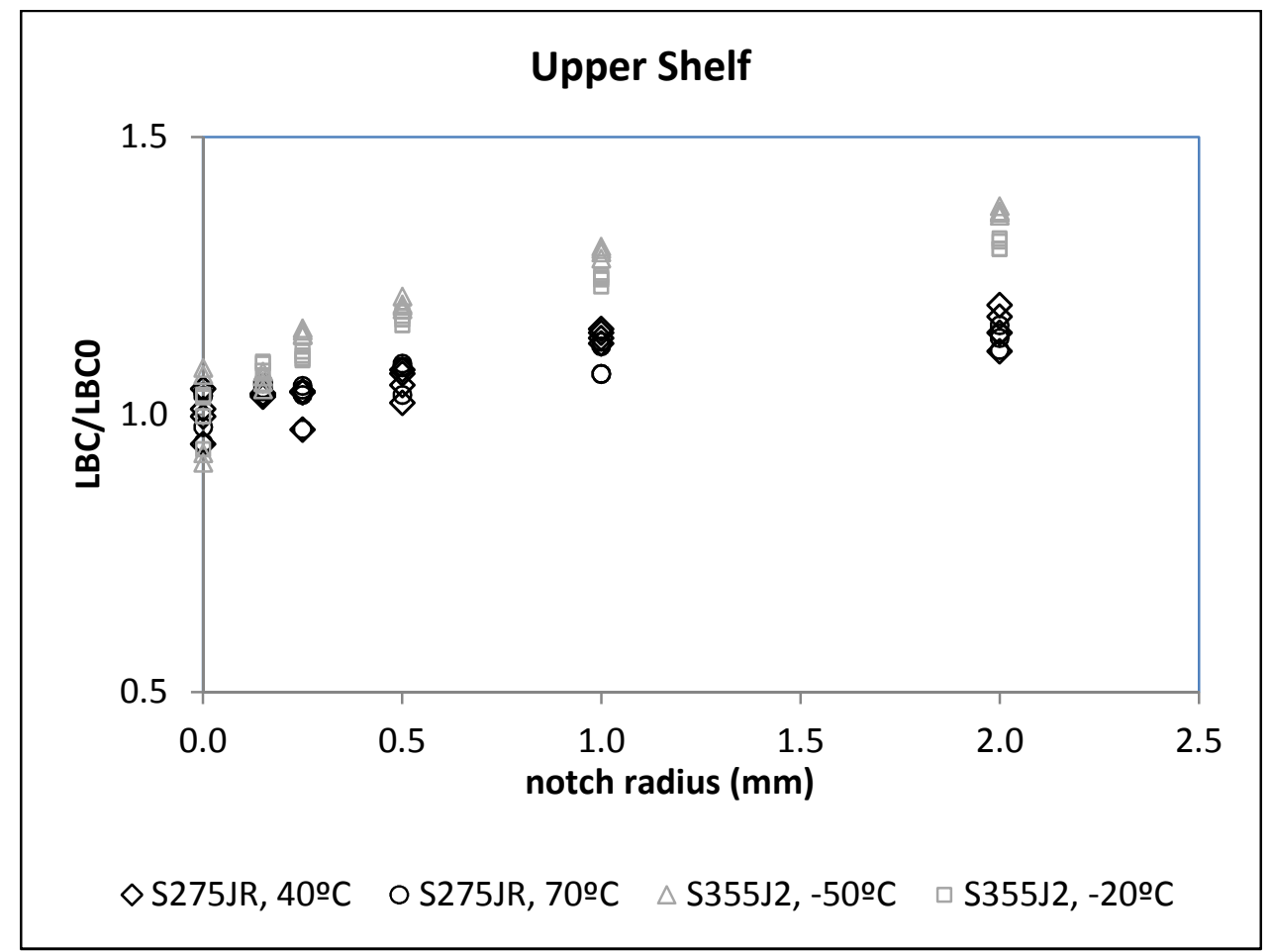

Figure 7. Load bearing capacity (LBC) results at upper shelf. 


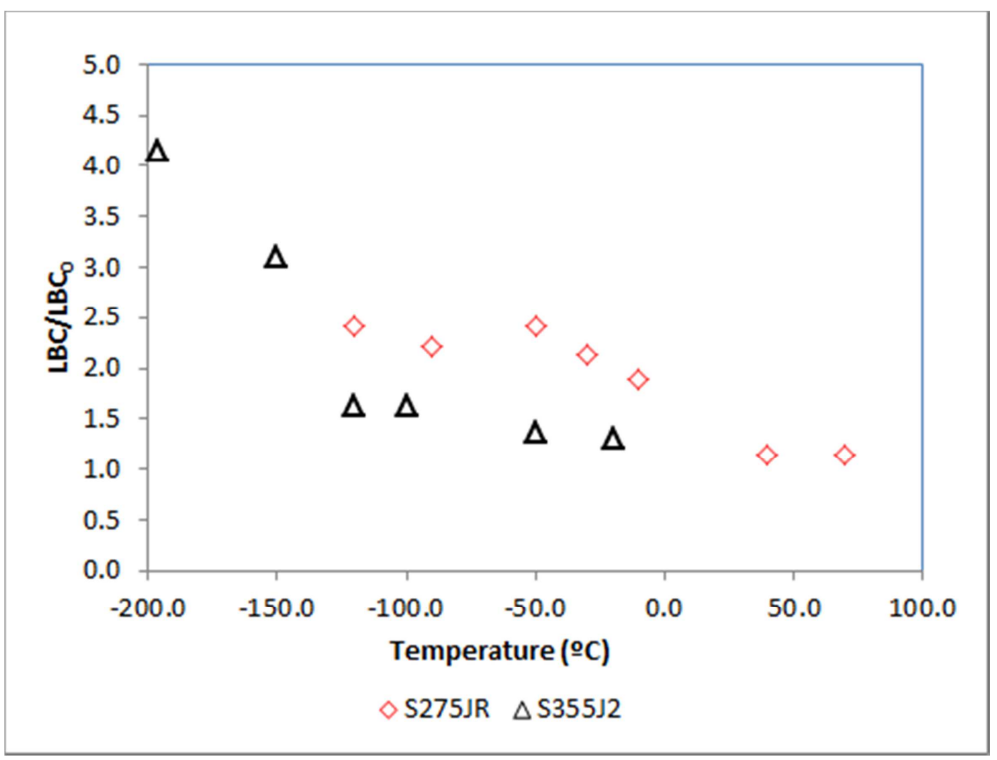

Figure 8. Variation of notch effect with temperature, measured by the ratio $\mathrm{LBC} / \mathrm{LBC}_{0}$. $\mathrm{LBC}$ represents the average $\mathrm{LBC}$ of specimens with $2.0 \mathrm{~mm}$ notch radius; $\mathrm{LBC}_{0}$ represents the average LBC of cracked specimens. 


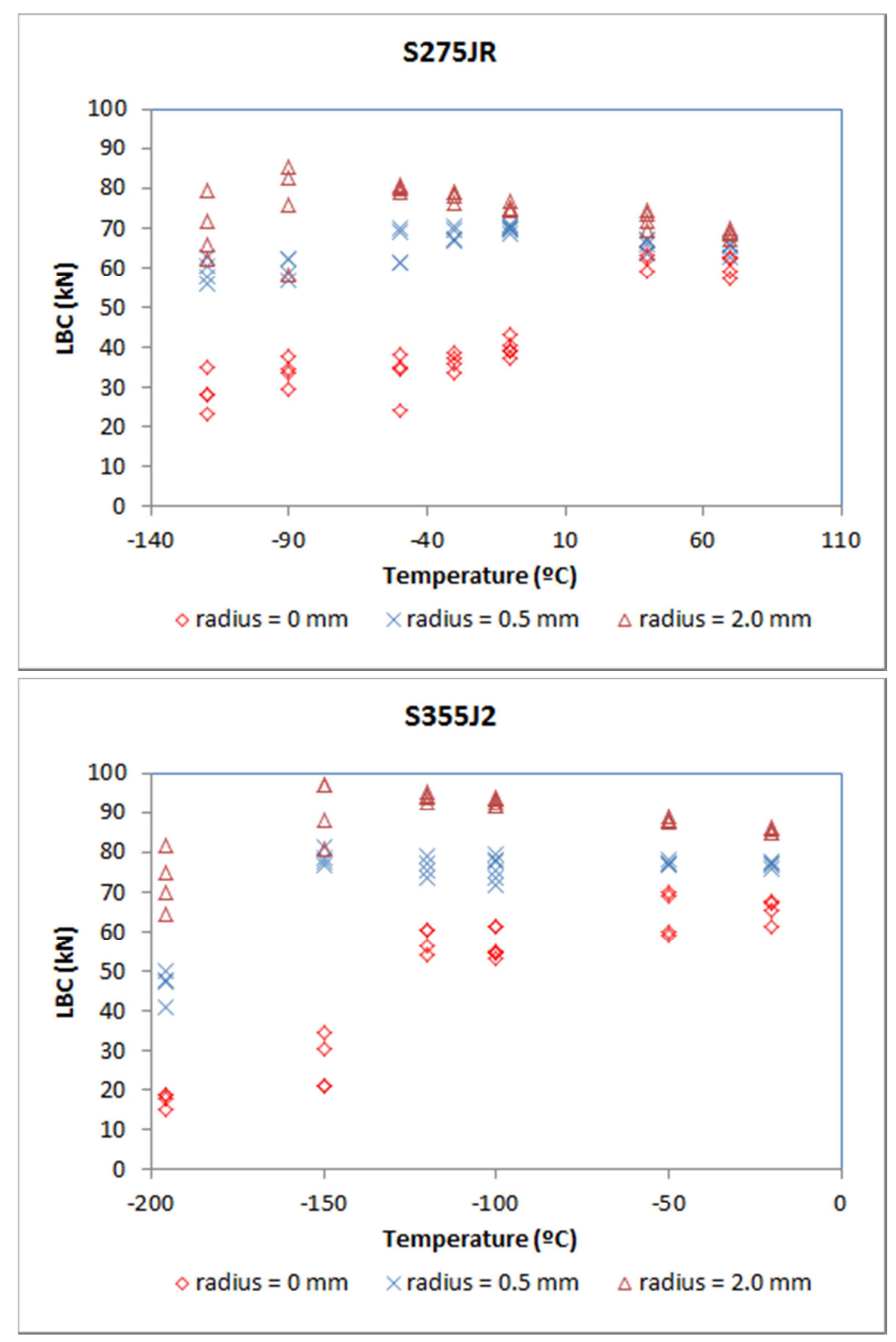

Figure 9. Variation of LBC with temperature for notch radii of $0 \mathrm{~mm}, 0.5 \mathrm{~mm}$ and $2.0 \mathrm{~mm}$. 


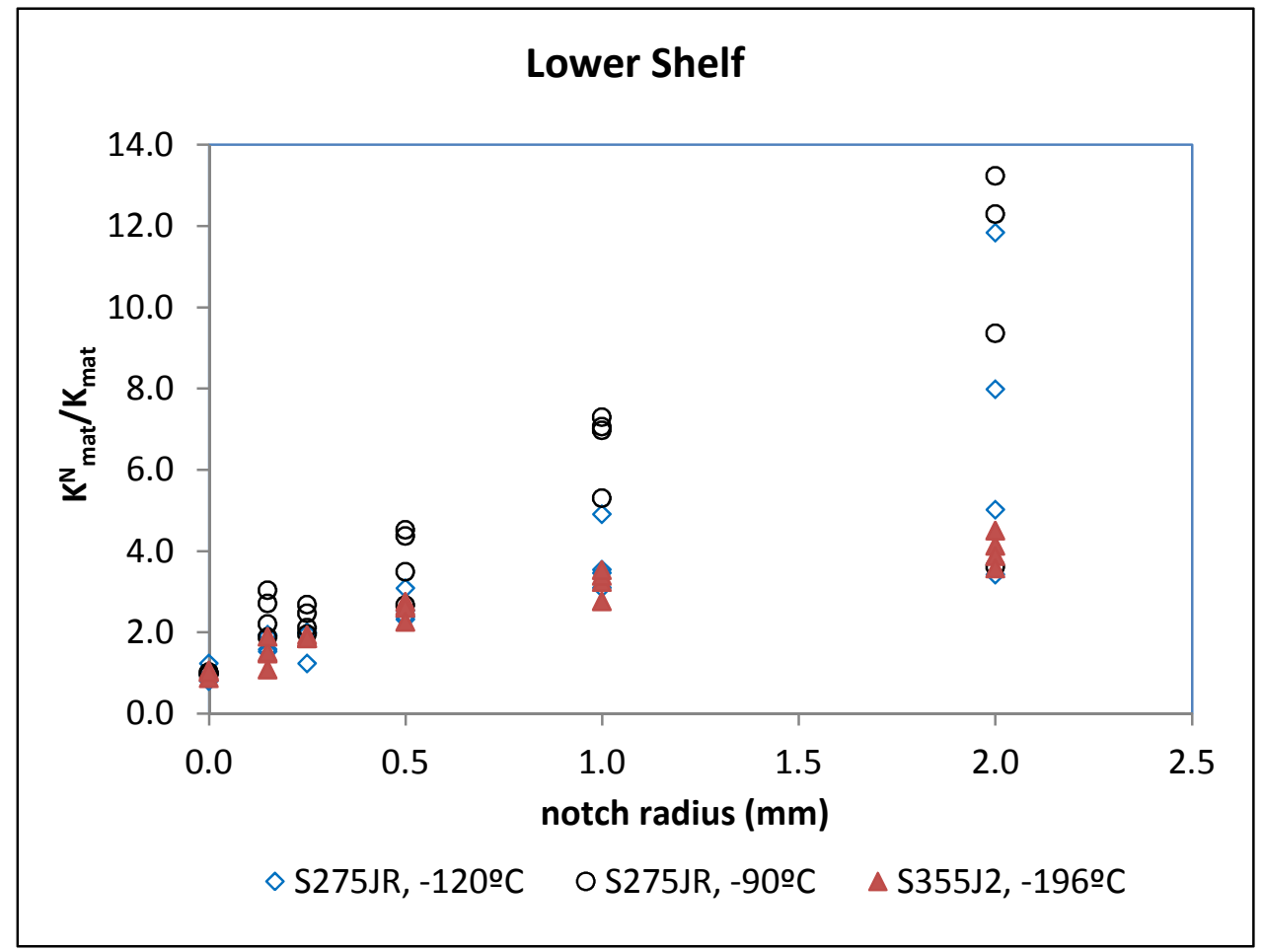

Figure 10. Apparent fracture toughness $\left(\mathrm{K}^{\mathrm{N}}{ }_{\text {mat }}\right)$ results at lower shelf. 

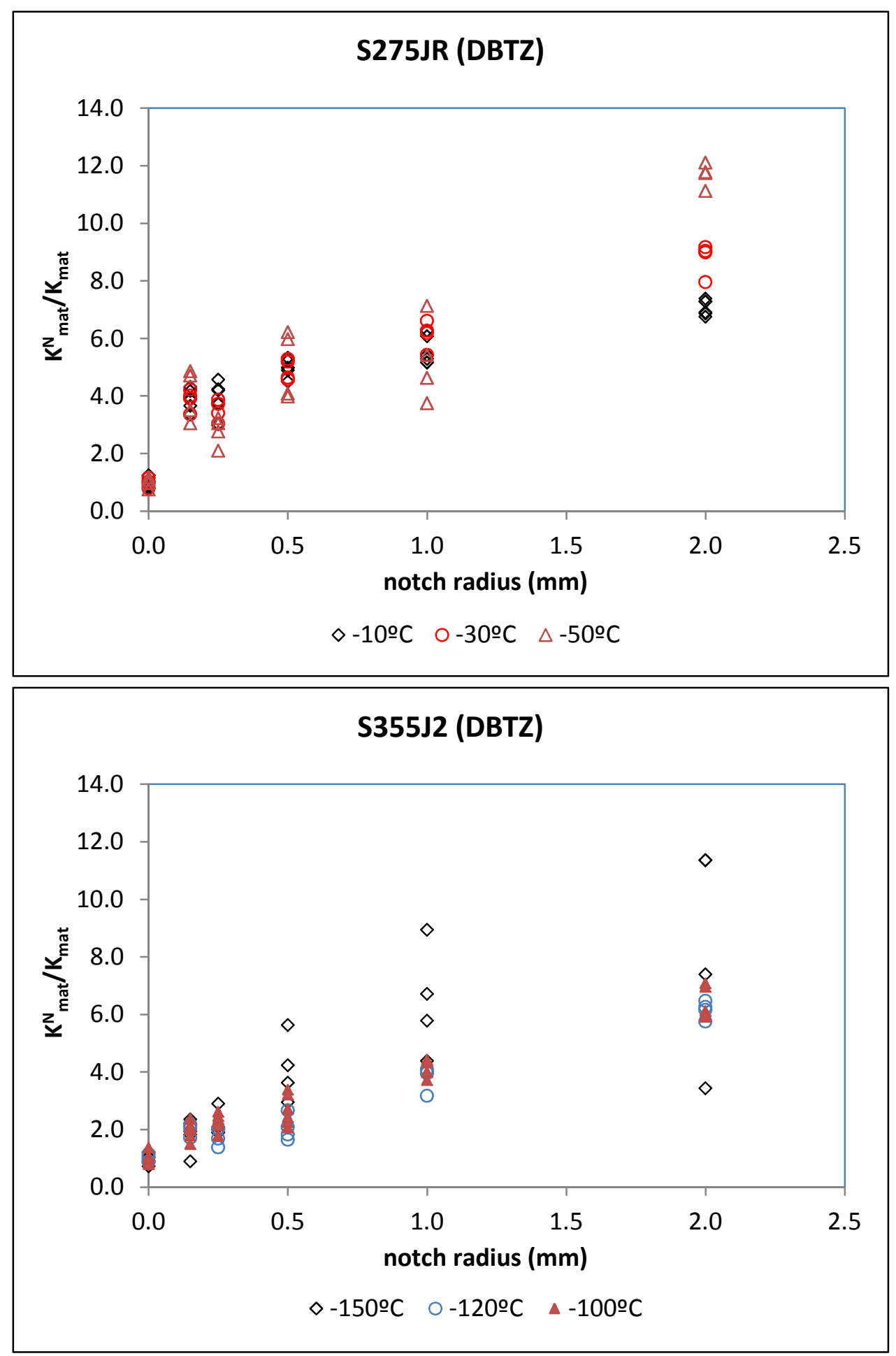

Figure 11. Apparent fracture toughness $\left(\mathrm{K}^{\mathrm{N}}{ }_{\text {mat }}\right)$ results at ductile-to-brittle transition zone. 


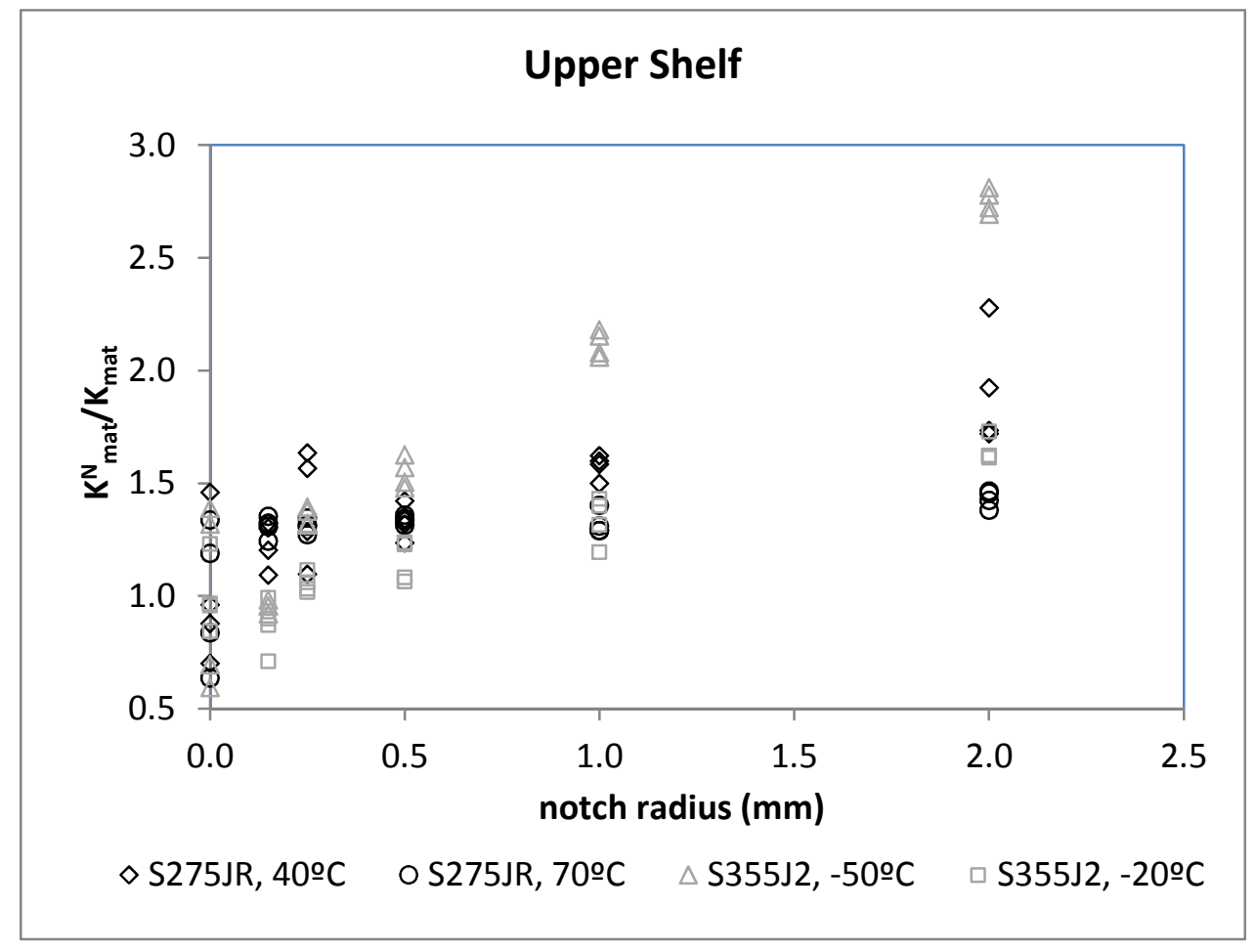

Figure 12. Apparent fracture toughness $\left(\mathrm{K}^{\mathrm{N}}{ }_{\text {mat }}\right)$ results at upper shelf. 


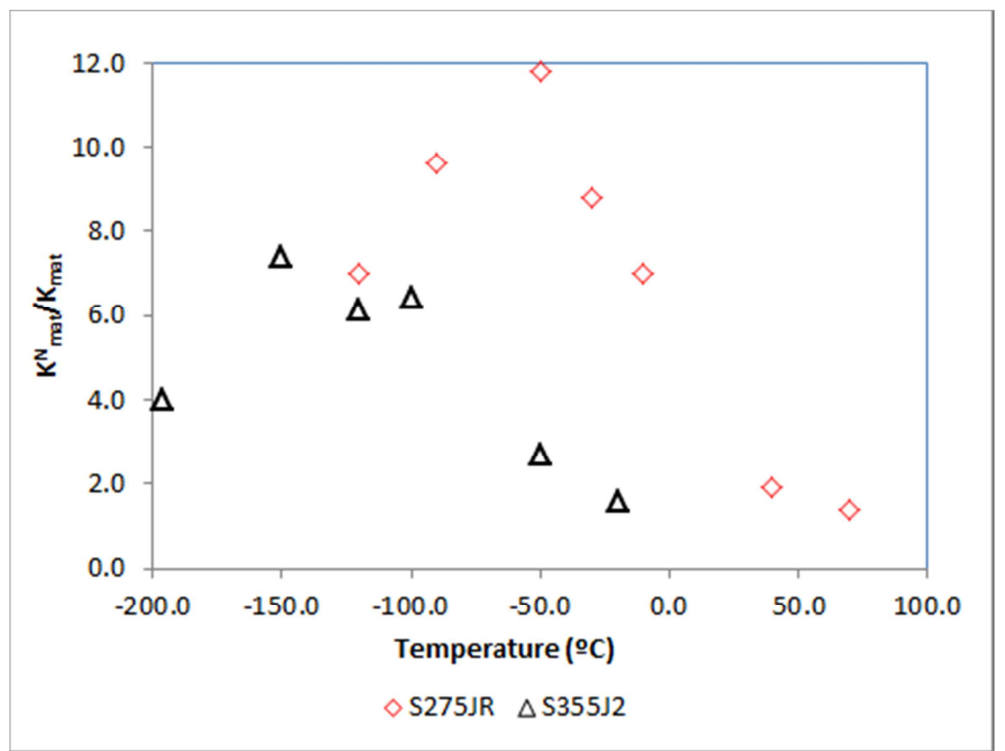

Figure 13. Variation of notch effect with temperature, measured by the ratio $\mathrm{K}^{\mathrm{N}}{ }_{\text {mat }} / \mathrm{K}^{\mathrm{N}}{ }_{\text {mat }} \cdot \mathrm{K}^{\mathrm{N}}{ }_{\text {mat }}$ represents the average apparent fracture toughness of specimens with $2.0 \mathrm{~mm}$ notch radius; $\mathrm{K}_{\text {mat }}$ represents the average fracture toughness of cracked specimens. 


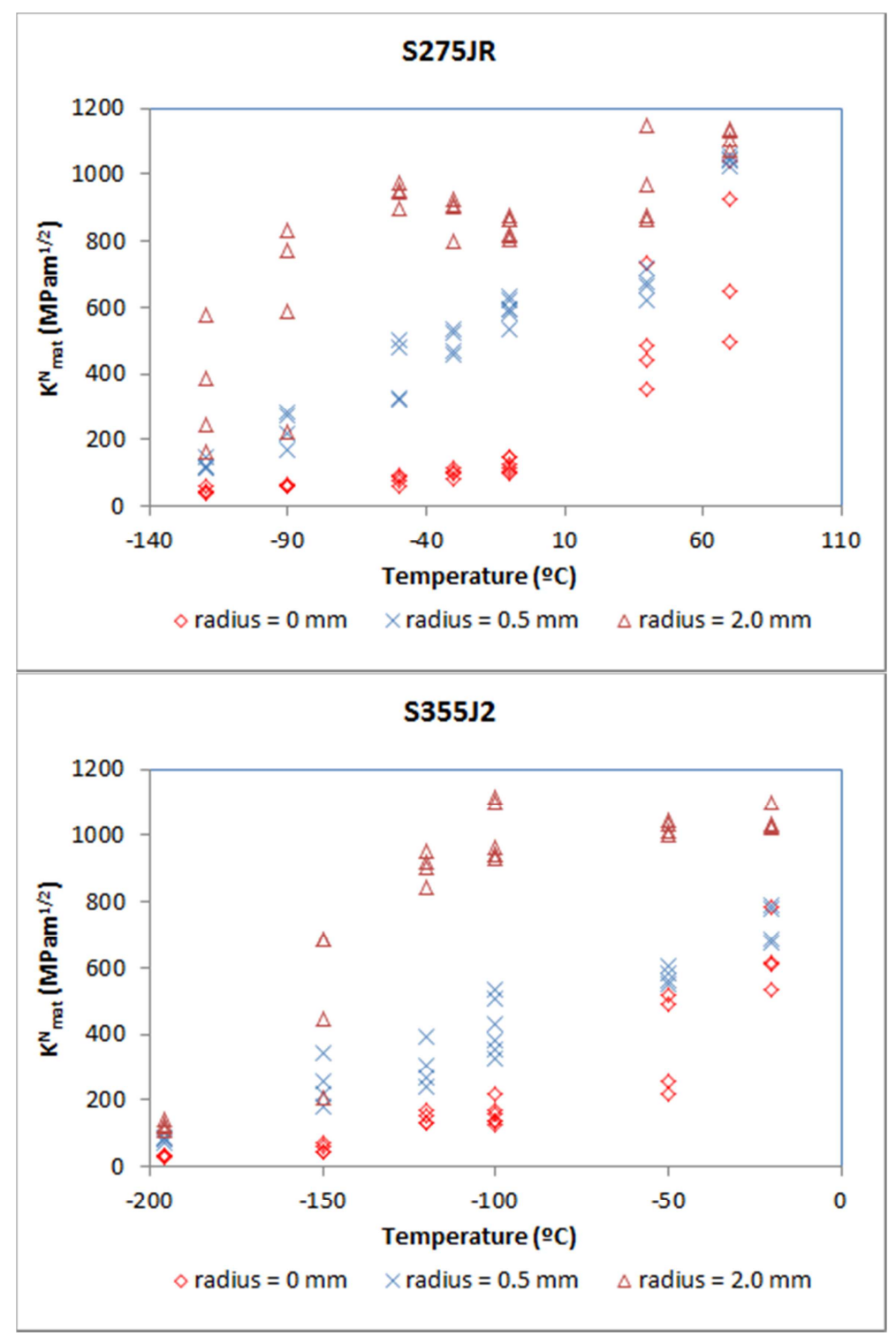

Figure 14. Variation of $\mathrm{K}^{\mathrm{N}}$ mat with temperature for notch radii of $0 \mathrm{~mm}, 0.5 \mathrm{~mm}$ and $2.0 \mathrm{~mm}$. 

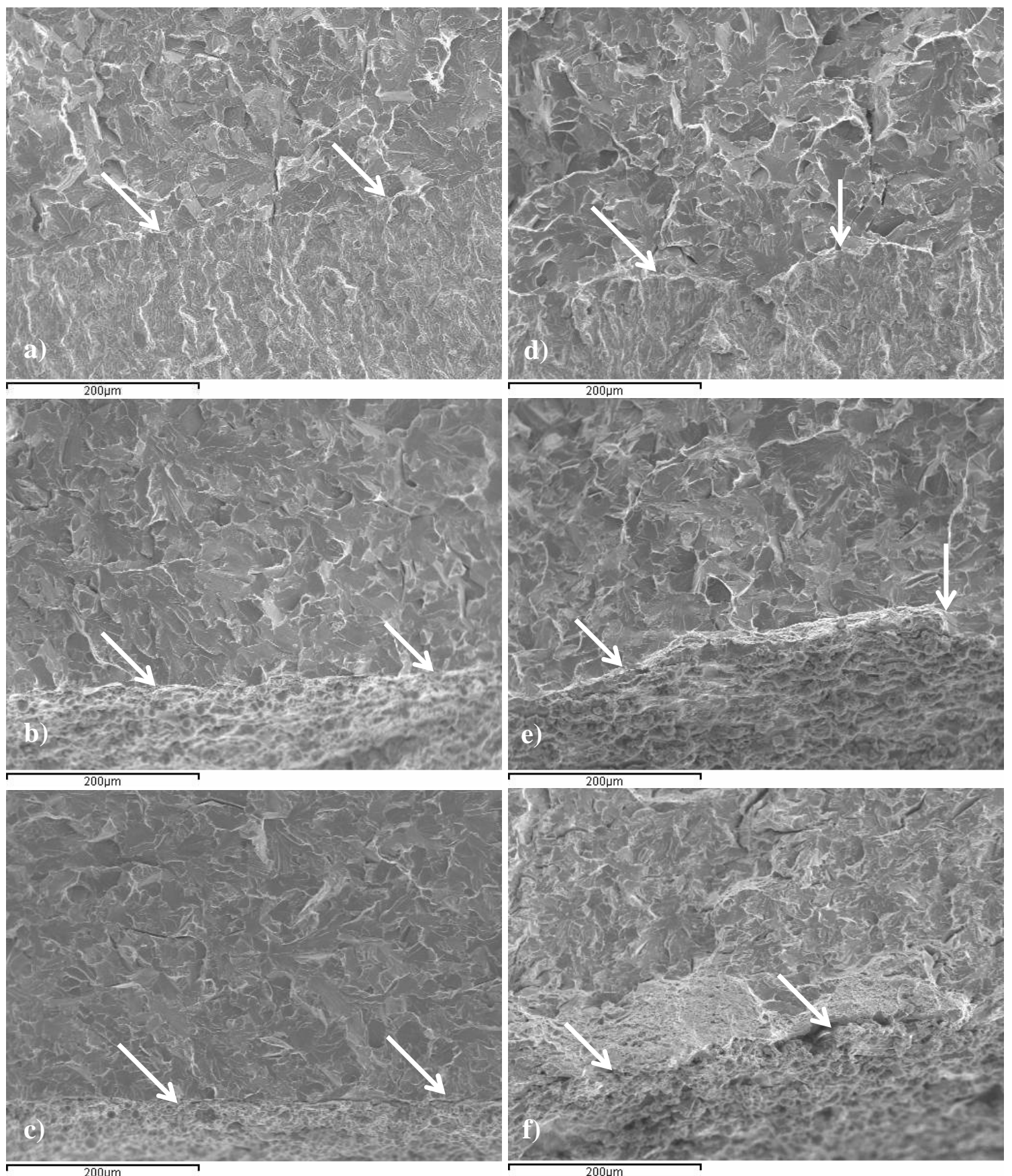

Figure 15. Fracture micromechanisms in steel S275JR at the lower shelf: a) $\rho=0 \mathrm{~mm}$, specimen $2.4\left(-120^{\circ} \mathrm{C}\right)$; b) $\rho=0.5 \mathrm{~mm}$, specimen $2.13\left(-120^{\circ} \mathrm{C}\right)$; c) $\rho=2.0 \mathrm{~mm}$, specimen $2.23(-$ $\left.120^{\circ} \mathrm{C}\right)$; d) $\rho=0 \mathrm{~mm}$, specimen $2.28\left(-90^{\circ} \mathrm{C}\right)$; e) $\rho=0.5 \mathrm{~mm}$, specimen $2.39\left(-90^{\circ} \mathrm{C}\right)$; f $\rho=2.0$ $\mathrm{mm}$, specimen $2.46\left(-90^{\circ} \mathrm{C}\right)$. The arrows indicate the initial defect front. 

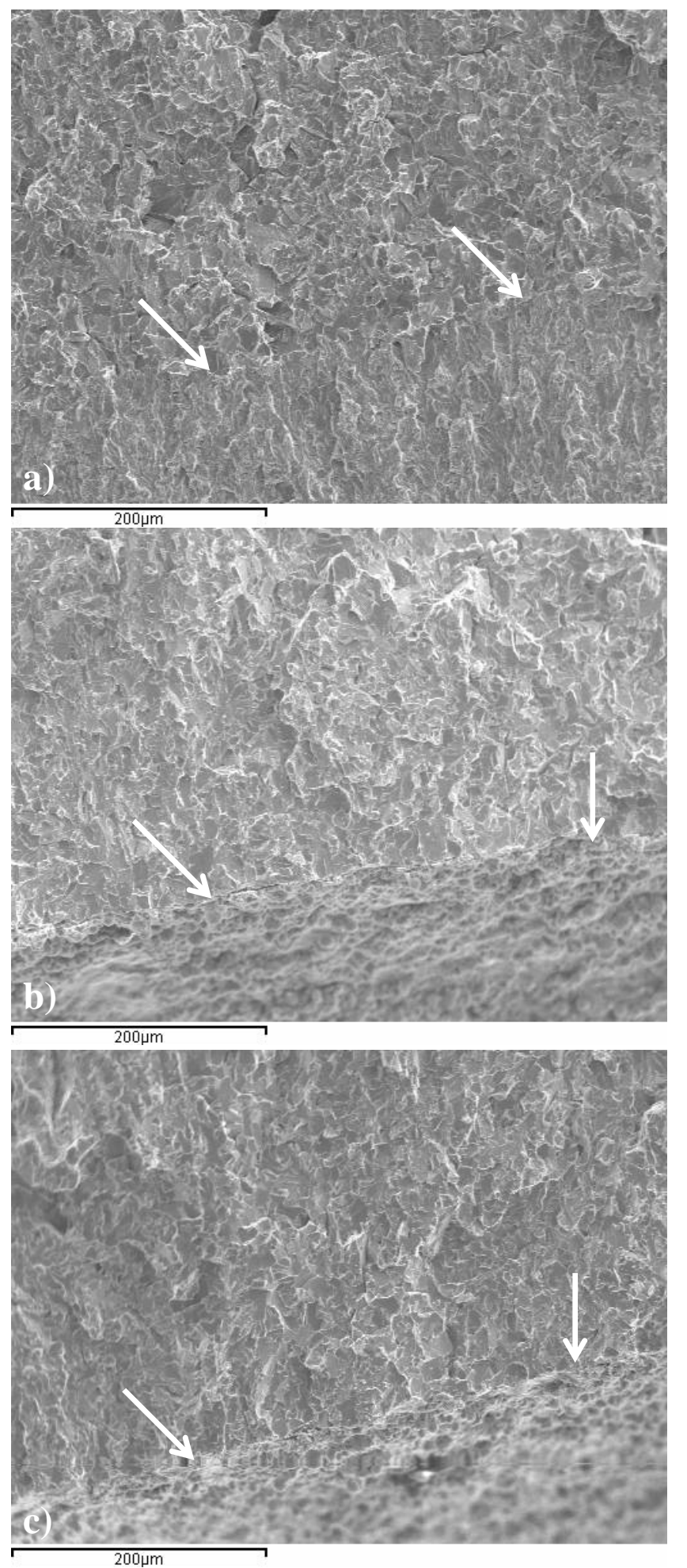

Figure 16. Fracture micromechanisms in steel S355J2 at the lower shelf $\left(-196^{\circ} \mathrm{C}\right)$ : a) $\rho=0 \mathrm{~mm}$, specimen 3.4 ; b) $\rho=0.5 \mathrm{~mm}$, specimen 3.15 ; c) $\rho=2.0 \mathrm{~mm}$, specimen 3.21 . The arrows indicate the initial defect front. 

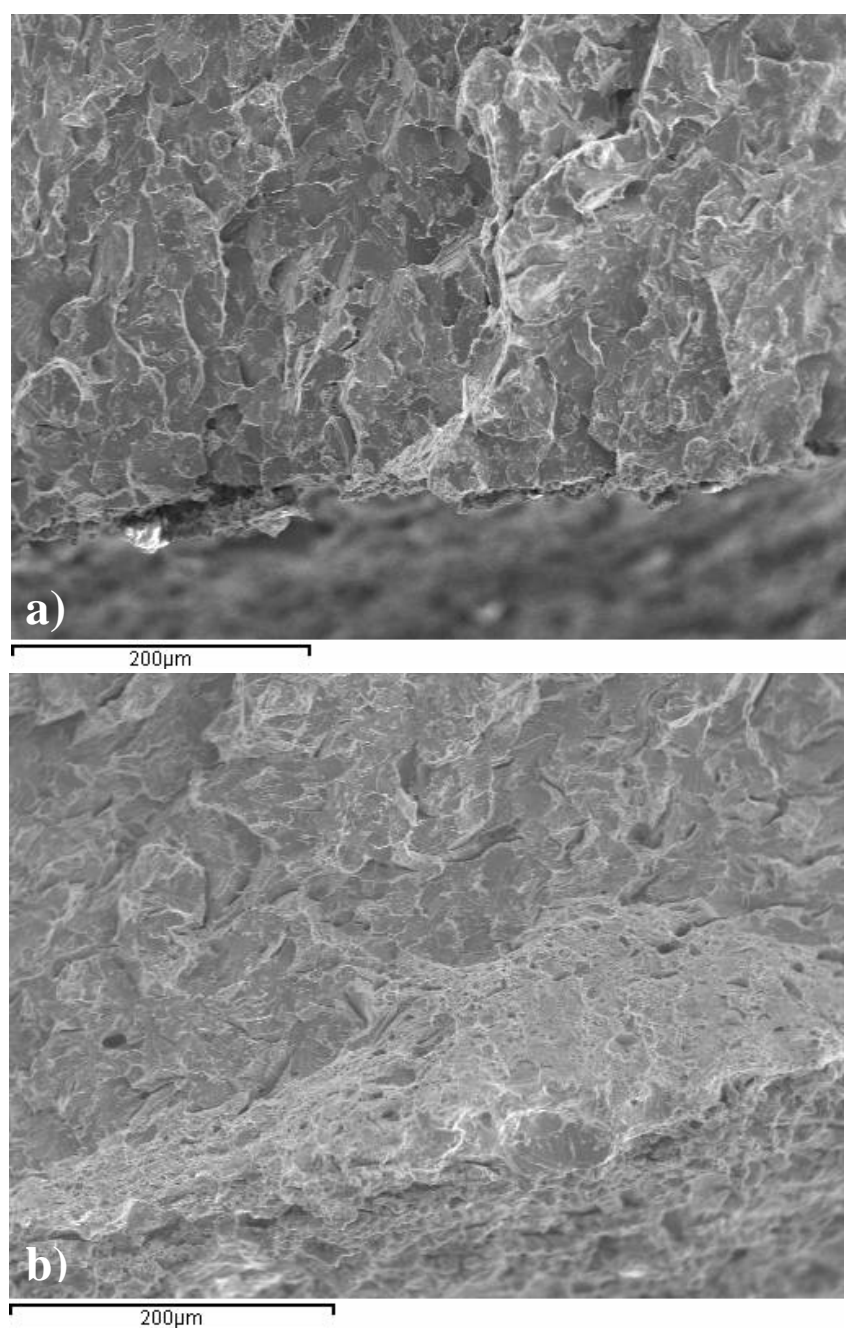

Figure 17. Fracture micromechanisms in steel $\mathrm{S} 275 \mathrm{JR}$ at $-90^{\circ} \mathrm{C}:$ a) notch radius $=2.0 \mathrm{~mm}$, specimen $\left.2.45, \mathrm{~K}^{\mathrm{N}}{ }_{\text {aat }}=226.6 \mathrm{MPam}^{1 / 2} ; \mathrm{b}\right)$ notch radius $=2.0 \mathrm{~mm}$, specimen $2.48, \mathrm{~K}^{\mathrm{N}}{ }_{\text {mat }}=830.8$ $\mathrm{MPam}^{1 / 2}$. 

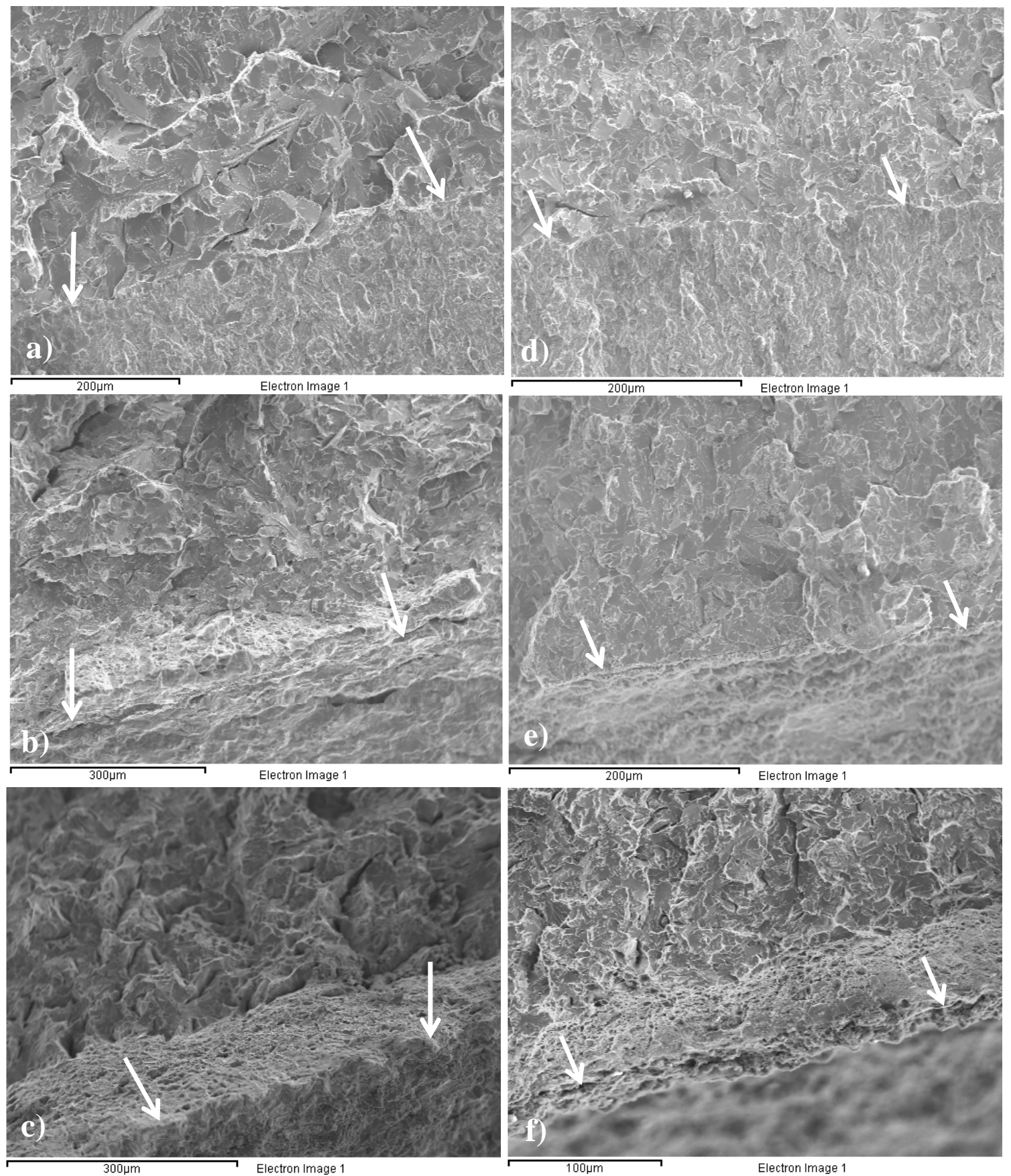

Figure 18. Fracture micromechanisms observed in the DBTZ : a) $\rho=0 \mathrm{~mm}$, specimen $2-51$ $\left(\mathrm{S} 275 \mathrm{JR},-50^{\circ} \mathrm{C}\right)$; b) $\rho=0.15 \mathrm{~mm}$, specimen 2-53 (S275JR, $\left.-50^{\circ} \mathrm{C}\right)$; c) $\rho=2.0 \mathrm{~mm}$, specimen 2$71\left(\mathrm{~S} 275 \mathrm{JR},-50{ }^{\circ} \mathrm{C}\right)$; d $\rho=0 \mathrm{~mm}$, specimen $3-27\left(\mathrm{~S} 355 \mathrm{~J} 2,-150^{\circ} \mathrm{C}\right)$ e) $\rho=0.25 \mathrm{~mm}$, specimen 3-33 (S355J2, $\left.-150^{\circ} \mathrm{C}\right)$; f $\rho=1.0 \mathrm{~mm}$, specimen $3-42\left(\mathrm{~S} 355 \mathrm{~J} 2,-150^{\circ} \mathrm{C}\right)$. The arrows indicate the initial notch front. 

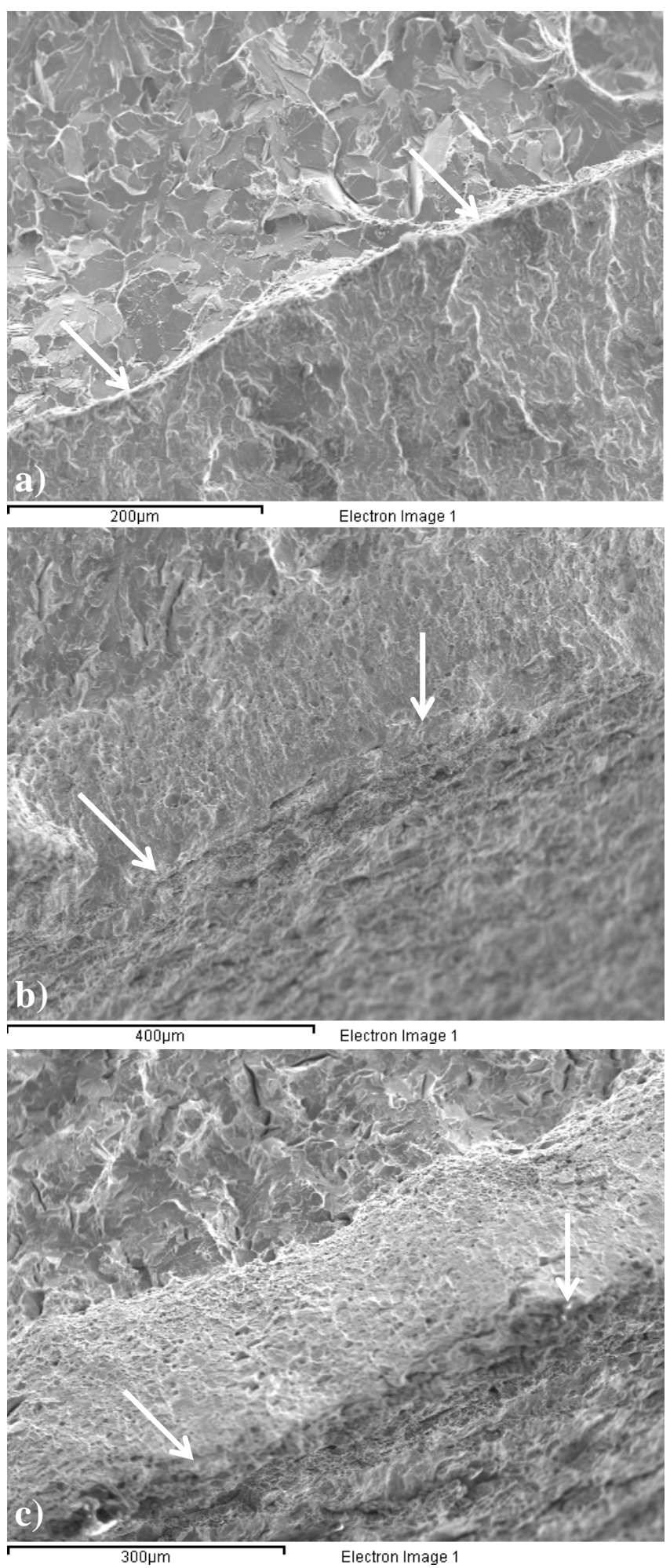

Figure 19. Fracture micromechanisms in steel $\mathrm{S} 275 \mathrm{JR}$ at $-10^{\circ} \mathrm{C}$ : a) notch radius $=0 \mathrm{~mm}$, specimen 2-99; b) notch radius $=0.5 \mathrm{~mm}$, specimen 2-118; c) notch radius $=2.0 \mathrm{~mm}$, specimen 2-131. The arrows indicate the initial defect front. 

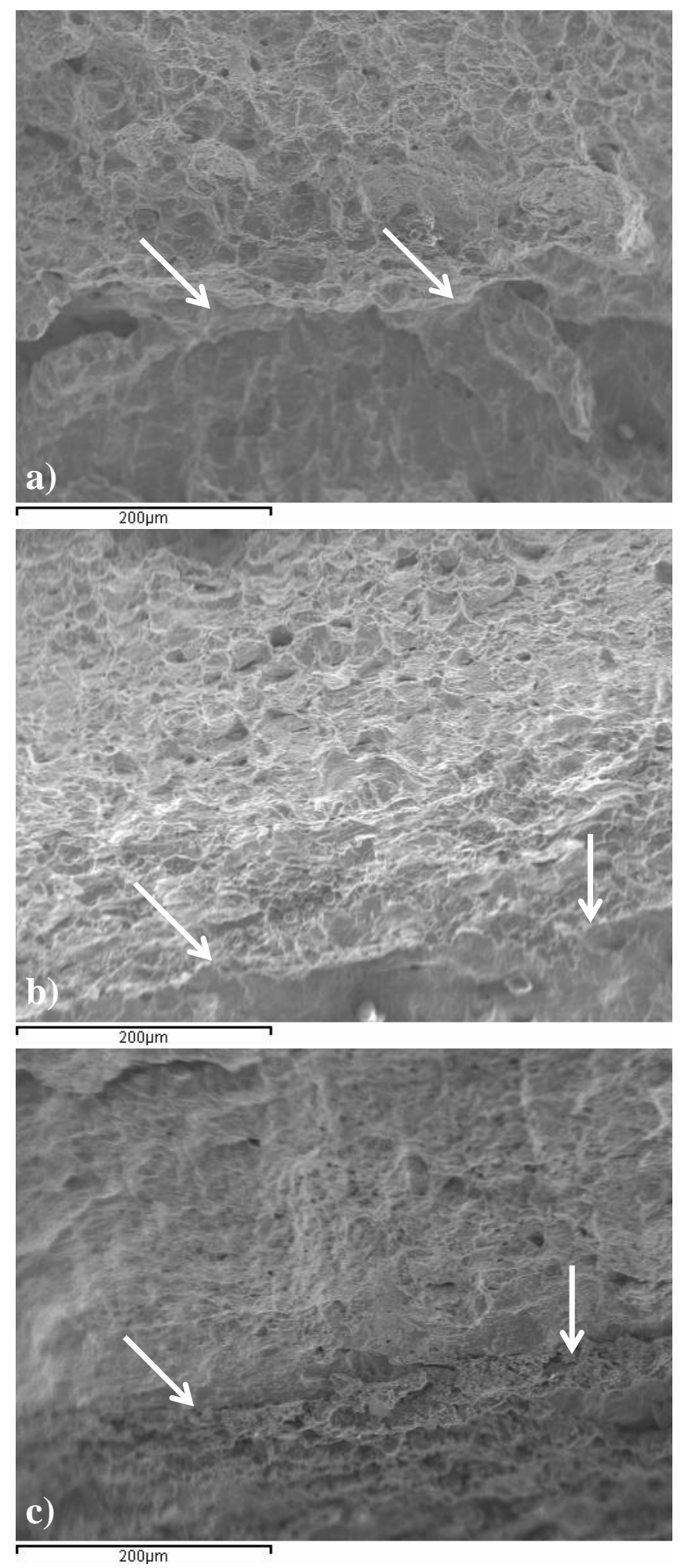

Figure 20. Fracture micromechanisms in steel $\mathrm{S} 275 \mathrm{JR}$ at $40^{\circ} \mathrm{C}$ : a) notch radius $=0 \mathrm{~mm}$, specimen 2-134; b) notch radius $=0.5 \mathrm{~mm}$, specimen $2-147$; ) notch radius $=2.0 \mathrm{~mm}$, specimen 2-153. The arrows indicate the initial defect front. 
Table 1. Chemical composition of the two steels being analysed: S275JR and S355J2

\begin{tabular}{|l|c|c|c|c|c|c|c|c|c|c|c|c|}
\hline & $\mathbf{C}$ & $\mathbf{S i}$ & $\mathbf{M n}$ & $\mathbf{P}$ & $\mathbf{S}$ & $\mathbf{~ N i}$ & $\mathbf{C r}$ & $\mathbf{M o}$ & $\mathbf{V}$ & $\mathbf{C u}$ & $\mathbf{T i}$ & $\mathbf{A l}$ \\
\hline $\mathbf{S 2 7 5 J R}$ & 0.18 & 0.26 & 1.18 & 0.012 & 0.009 & $<0.085$ & $<0.018$ & $<0.12$ & $<0.020$ & $<0.06$ & $<0.022$ & 0.034 \\
\hline S355J2 & 0.20 & 0.31 & 1.39 & $<0.012$ & 0.008 & 0.09 & 0.05 & $<0.12$ & 0.02 & $<0.06$ & $<0.022$ & 0.014 \\
\hline
\end{tabular}


Table 2. Tensile properties of the two materials being analysed.

\begin{tabular}{|c|c|c|c|c|}
\hline Material & Temperature $\left({ }^{\mathbf{o}} \mathbf{C}\right)$ & $\mathbf{E}(\mathbf{G P a})$ & $\boldsymbol{\sigma}_{\mathbf{v}}(\mathbf{M P a})$ & $\boldsymbol{\sigma}_{\mathbf{u}}(\mathbf{M P a})$ \\
\hline \multirow{4}{*}{ S275JR } & +70 & 203 & 331.7 & 492.7 \\
\cline { 2 - 5 } & +40 & 205 & 331.0 & 504.7 \\
\cline { 2 - 5 } & +20 & 207 & 328.4 & 518.5 \\
\cline { 2 - 5 } & -10 & 207 & 337.6 & 536.3 \\
\cline { 2 - 5 } & -30 & 208 & 344.5 & 548.6 \\
\cline { 2 - 5 } & -50 & 209 & 349.1 & 564.7 \\
\cline { 2 - 5 } & -90 & 211 & 380.2 & 597.3 \\
\hline \multirow{4}{*}{ S355J2 } & -120 & 213 & 398.2 & 613.8 \\
\cline { 2 - 5 } & +20 & 207 & 374.6 & 557.6 \\
\cline { 2 - 5 } & -20 & 208 & 385.3 & 587.7 \\
\cline { 2 - 5 } & -50 & 209 & 395.3 & 602.7 \\
\cline { 2 - 5 } & -100 & 212 & 426.2 & 646.5 \\
\cline { 2 - 5 } & -120 & 212 & 459.8 & 671.6 \\
\hline
\end{tabular}


Table 3. Description of specimens and experimental results. Steel S275JR.

\begin{tabular}{|c|c|c|c|c|c|c|c|c|c|}
\hline Specimen & $\begin{array}{c}\text { Temperature } \\
\left({ }^{\circ} \mathrm{C}\right)\end{array}$ & $\begin{array}{c}\rho \\
(\mathbf{m m})\end{array}$ & $\begin{array}{l}\mathrm{LBC} \\
(\mathrm{kN})\end{array}$ & $\begin{array}{c}\mathbf{K}^{\mathbf{N}}{ }_{\text {mat }} \\
\left(\mathbf{M P a m}^{1 / 2}\right)\end{array}$ & Specimen & \begin{tabular}{|c|} 
Temperature \\
$\left({ }^{\circ} \mathrm{C}\right)$
\end{tabular} & $\begin{array}{c}\mathbf{\rho} \\
(\mathbf{m m})\end{array}$ & $\begin{array}{l}\text { LBC } \\
(\mathrm{kN})\end{array}$ & $\begin{array}{c}\mathbf{K}^{\mathrm{N}}{ }_{\text {mat }} \\
\left(\mathbf{M P a m}^{1 / 2}\right)\end{array}$ \\
\hline $2-1$ & \multirow{24}{*}{$\begin{array}{l}-120 \\
\text { (LS) }\end{array}$} & \multirow{4}{*}{0} & \begin{tabular}{|l|}
23.3 \\
\end{tabular} & 39.2 & $2-49$ & & \multirow{4}{*}{0} & 24.0 & 61.3 \\
\hline $2-2$ & & & \begin{tabular}{|l|}
35.2 \\
\end{tabular} & 60.4 & $2-50$ & & & 38.2 & 88.0 \\
\hline $2-3$ & & & 28.0 & 46.8 & $2-51$ & & & 34.6 & 78.1 \\
\hline $2-4$ & & & - & - & $2-52$ & & & \begin{tabular}{|l|}
34.9 \\
\end{tabular} & 95.0 \\
\hline $2-5$ & & \multirow{4}{*}{0.15} & \begin{tabular}{|l|l|}
43.4 \\
\end{tabular} & 75.0 & $2-53$ & & \multirow{4}{*}{0.15} & \begin{tabular}{|l|}
59.9 \\
\end{tabular} & 283.2 \\
\hline $2-6$ & & & \begin{tabular}{|l|}
44.6 \\
\end{tabular} & 77.0 & $2-54$ & & & \begin{tabular}{|l|}
58.5 \\
\end{tabular} & 246.3 \\
\hline $2-7$ & & & \begin{tabular}{|l|}
54.9 \\
\end{tabular} & 94.8 & $2-55$ & & & \begin{tabular}{|l|}
65.2 \\
\end{tabular} & 392.5 \\
\hline $2-8$ & & & \begin{tabular}{|l|}
54.1 \\
\end{tabular} & 93.6 & $2-56$ & & & \begin{tabular}{|l|}
64.2 \\
\end{tabular} & 379.9 \\
\hline $2-9$ & & \multirow{4}{*}{0.25} & \begin{tabular}{|l|}
56.3 \\
\end{tabular} & 97.4 & $2-57$ & & \multirow{4}{*}{0.25} & 57.0 & 223.7 \\
\hline $2-10$ & & & \begin{tabular}{|l|}
34.9 \\
\end{tabular} & 60.3 & $2-58$ & & & 58.0 & 260.9 \\
\hline $2-11$ & & & \begin{tabular}{|l|}
55.8 \\
\end{tabular} & 96.5 & $2-59$ & & & \begin{tabular}{|l|}
57.4 \\
\end{tabular} & 246.6 \\
\hline $2-12$ & & & \begin{tabular}{|l|}
56.6 \\
\end{tabular} & 97.9 & $2-60$ & -50 & & \begin{tabular}{|l|}
53.6 \\
\end{tabular} & 169.9 \\
\hline $2-13$ & & \multirow{4}{*}{0.50} & 60.6 & 123.6 & $2-61$ & (DBTZ) & \multirow{4}{*}{0.50} & 61.5 & 330.1 \\
\hline $2-14$ & & & \begin{tabular}{|l|}
57.5 \\
\end{tabular} & 116.0 & $2-62$ & & & \begin{tabular}{|l|}
61.1 \\
\end{tabular} & 321.8 \\
\hline $2-15$ & & & \begin{tabular}{|l|}
55.9 \\
\end{tabular} & 113.3 & $2-63$ & & & \begin{tabular}{|l|}
69.8 \\
\end{tabular} & $\begin{array}{l}501.9 \\
\end{array}$ \\
\hline $2-16$ & & & 62.5 & 150.6 & $2-64$ & & & \begin{tabular}{|l|}
69.2 \\
\end{tabular} & 481.9 \\
\hline $2-17$ & & \multirow{4}{*}{1.0} & 66.5 & 239.6 & $2-65$ & & \multirow{4}{*}{1.0} & 59.5 & 302.5 \\
\hline $2-18$ & & & \begin{tabular}{|l|}
63.2 \\
\end{tabular} & 151.4 & $2-66$ & & & \begin{tabular}{|l|}
66.3 \\
\end{tabular} & 437.7 \\
\hline $2-19$ & & & \begin{tabular}{|l|}
64.0 \\
\end{tabular} & $\begin{array}{l}172.9 \\
\end{array}$ & $2-67$ & & & 63.5 & 374.0 \\
\hline $2-20$ & & & \begin{tabular}{|l|}
63.6 \\
\end{tabular} & 169.3 & $2-68$ & & & \begin{tabular}{|l|}
72.5 \\
\end{tabular} & 575.2 \\
\hline $2-21$ & & \multirow{4}{*}{2.0} & \begin{tabular}{|l|}
62.1 \\
\end{tabular} & 167.1 & $2-69$ & & \multirow{4}{*}{2.0} & \begin{tabular}{|l|}
80.8 \\
\end{tabular} & 950.3 \\
\hline $2-22$ & & & 79.5 & 578.2 & $2-70$ & & & 80.3 & 976.2 \\
\hline $2-23$ & & & \begin{tabular}{|l|}
71.9 \\
\end{tabular} & 389.6 & $2-71$ & & & \begin{tabular}{|l|}
79.8 \\
\end{tabular} & 947.4 \\
\hline $2-24$ & & & \begin{tabular}{|l|}
65.8 \\
\end{tabular} & 245.1 & $2-72$ & & & \begin{tabular}{|l|}
78.9 \\
\end{tabular} & 897.2 \\
\hline $2-25$ & \multirow{24}{*}{$\begin{array}{c}-90 \\
(\mathrm{LS})\end{array}$} & \multirow{4}{*}{0} & \begin{tabular}{|l|}
29.8 \\
\end{tabular} & 64.6 & $2-73$ & & \multirow{4}{*}{0} & \begin{tabular}{|l|}
37.1 \\
\end{tabular} & 104.2 \\
\hline $2-26$ & & & \begin{tabular}{|l|}
34.6 \\
\end{tabular} & 60.5 & $2-74$ & & & 33.6 & 80.8 \\
\hline $2-27$ & & & \begin{tabular}{|l|}
33.8 \\
\end{tabular} & 63.1 & $2-75$ & & & \begin{tabular}{|l|}
38.5 \\
\end{tabular} & 100.1 \\
\hline $2-28$ & & & \begin{tabular}{|l|}
37.6 \\
\end{tabular} & 62.7 & $2-76$ & & & 36.0 & 117.7 \\
\hline $2-29$ & & \multirow{4}{*}{0.15} & \begin{tabular}{|l|}
57.0 \\
\end{tabular} & 170.3 & $2-77$ & & \multirow{4}{*}{0.15} & \begin{tabular}{|l|}
63.1 \\
\end{tabular} & 395.3 \\
\hline $2-30$ & & & \begin{tabular}{|l|}
52.9 \\
\end{tabular} & 118.6 & $2-78$ & & & 65.4 & 426.1 \\
\hline $2-31$ & & & \begin{tabular}{|l|}
57.7 \\
\end{tabular} & 190.4 & $2-79$ & & & \begin{tabular}{|l|}
64.1 \\
\end{tabular} & 405.3 \\
\hline $2-32$ & & & \begin{tabular}{|l|}
56.5 \\
\end{tabular} & 138.9 & $2-80$ & & & \begin{tabular}{|l|}
62.1 \\
\end{tabular} & 339.8 \\
\hline $2-33$ & & \multirow{4}{*}{0.25} & \begin{tabular}{|l|}
57.0 \\
\end{tabular} & 154.9 & $2-81$ & & \multirow{4}{*}{0.25} & 63.6 & 390.1 \\
\hline $2-34$ & & & \begin{tabular}{|l|}
55.6 \\
\end{tabular} & 122.9 & $2-82$ & & & \begin{tabular}{|l|}
63.4 \\
\end{tabular} & 376.4 \\
\hline 2-35 & & & \begin{tabular}{|l|}
58.7 \\
\end{tabular} & 168.7 & $2-83$ & & & \begin{tabular}{|l|}
61.6 \\
\end{tabular} & 343.3 \\
\hline $2-36$ & & & \begin{tabular}{|l|}
56.4 \\
\end{tabular} & 132.8 & $2-84$ & -30 & & 59.2 & 306.9 \\
\hline 2-37 & & & 56.8 & 167.7 & $2-85$ & (DBTZ) & & \begin{tabular}{|l|}
66.9 \\
\end{tabular} & 460.4 \\
\hline $2-38$ & & 050 & \begin{tabular}{|l|}
62.4 \\
\end{tabular} & 284.2 & $2-86$ & & 050 & \begin{tabular}{|l|}
69.3 \\
\end{tabular} & 524.2 \\
\hline $2-39$ & & 0.50 & \begin{tabular}{|l|}
58.4 \\
\end{tabular} & 219.5 & $2-87$ & & 0.00 & \begin{tabular}{|l|}
70.3 \\
\end{tabular} & 533.7 \\
\hline $2-40$ & & & \begin{tabular}{|l|}
62.0 \\
\end{tabular} & 274.7 & $2-88$ & & & \begin{tabular}{|l|}
67.3 \\
\end{tabular} & 468.0 \\
\hline $2-41$ & & & \begin{tabular}{|l|}
71.1 \\
\end{tabular} & 458.2 & $2-89$ & & & \begin{tabular}{|l|}
73.2 \\
\end{tabular} & 632.3 \\
\hline $2-42$ & & & \begin{tabular}{|l|}
65.2 \\
\end{tabular} & 333.0 & $2-90$ & & 10 & \begin{tabular}{|l|}
72.9 \\
\end{tabular} & 624.1 \\
\hline $2-43$ & & 1.0 & 71.0 & 443.2 & 2-91 & & 1.0 & 70.0 & 547.7 \\
\hline $2-44$ & & & 71.0 & 437.5 & $2-92$ & & & \begin{tabular}{|l|l|}
73.7 \\
\end{tabular} & 667.1 \\
\hline $2-45$ & & & \begin{tabular}{|l|}
57.9 \\
\end{tabular} & 226.6 & $2-93$ & & & \begin{tabular}{|l|}
79.1 \\
\end{tabular} & 906.5 \\
\hline $2-46$ & & 20 & \begin{tabular}{|l|}
76.0 \\
\end{tabular} & 587.4 & $2-94$ & & 28 & \begin{tabular}{|l|}
76.3 \\
\end{tabular} & 801.9 \\
\hline $2-47$ & & 2.0 & \begin{tabular}{|l|}
82.5 \\
\end{tabular} & 771.6 & $2-95$ & & 2.0 & \begin{tabular}{|l|}
77.9 \\
\end{tabular} & 911.6 \\
\hline $2-48$ & & & \begin{tabular}{|l|}
85.1 \\
\end{tabular} & 830.8 & $2-96$ & & & \begin{tabular}{|l|}
78.9 \\
\end{tabular} & 924.3 \\
\hline
\end{tabular}


Table 3. Description of specimens and experimental results. Steel S275JR (cont.).

\begin{tabular}{|c|c|c|c|c|c|c|c|c|c|}
\hline Specimen & \begin{tabular}{|c} 
Temperature \\
$\left({ }^{\circ} \mathrm{C}\right)$
\end{tabular} & $\begin{array}{c}\rho \\
(\mathbf{m m})\end{array}$ & $\begin{array}{l}\text { LBC } \\
(\mathbf{k N})\end{array}$ & $\begin{array}{c}\mathbf{K}^{\mathbf{N}}{ }_{\text {mat }} \\
\left(\mathrm{MPam}^{1 / 2}\right)\end{array}$ & Specimen & \begin{tabular}{|c} 
Temperature \\
$\left({ }^{\circ} \mathrm{C}\right)$
\end{tabular} & $\begin{array}{c}\rho \\
(\mathbf{m m})\end{array}$ & $\begin{array}{l}\text { LBC } \\
(\mathbf{k N})\end{array}$ & $\begin{array}{c}\mathbf{K}^{\mathbf{N}}{ }_{\text {mat }}{ }_{\left(\mathrm{MPam}^{1 / 2}\right)} \\
\end{array}$ \\
\hline 2-97 & \multirow{36}{*}{$\begin{array}{c}-10 \\
\text { (DBTZ) }\end{array}$} & \multirow{6}{*}{0} & 43.0 & 148.5 & $2-139$ & \multirow{18}{*}{$\begin{array}{c}+40 \\
\text { (US) }\end{array}$} & \multirow{2}{*}{0.15} & 64.7 & 607.5 \\
\hline $2-98$ & & & 39.3 & 97.0 & $2-140$ & & & 64.5 & 658.1 \\
\hline $2-99$ & & & \begin{tabular}{|l|}
39.3 \\
\end{tabular} & 105.8 & $2-141$ & & \multirow{4}{*}{0.25} & 64.9 & 649.8 \\
\hline $2-100$ & & & 40.4 & 124.2 & $2-142$ & & & 64.8 & 554.1 \\
\hline $2-101$ & & & \begin{tabular}{|l|}
37.1 \\
\end{tabular} & 148.1 & $2-143$ & & & 60.6 & 790.6 \\
\hline $2-102$ & & & 39.2 & 113.2 & $2-144$ & & & 64.8 & 825.5 \\
\hline $2-103$ & & \multirow{6}{*}{0.15} & \begin{tabular}{|l|}
63.0 \\
\end{tabular} & 400.2 & $2-145$ & & \multirow{4}{*}{0.50} & 65.6 & 623.6 \\
\hline $2-104$ & & & \begin{tabular}{|l|}
65.8 \\
\end{tabular} & 465.0 & $2-146$ & & & 66.9 & 676.3 \\
\hline $2-105$ & & & 66.4 & 496.7 & $2-147$ & & & 67.3 & 665.5 \\
\hline $2-106$ & & & 65.6 & 461.1 & $2-148$ & & & 63.6 & 717.8 \\
\hline 2-107 & & & \begin{tabular}{|l|}
64.4 \\
\end{tabular} & 435.6 & $2-149$ & & \multirow{4}{*}{1.0} & 71.9 & 819.1 \\
\hline $2-108$ & & & 64.6 & 514.3 & $2-150$ & & & 71.5 & 807.4 \\
\hline $2-109$ & & \multirow{6}{*}{0.25} & \begin{tabular}{|l|l}
66.1 \\
\end{tabular} & 444.2 & $2-151$ & & & 70.3 & 757.2 \\
\hline $2-110$ & & & \begin{tabular}{|l|}
63.8 \\
\end{tabular} & 444.1 & $2-152$ & & & 70.9 & 800.4 \\
\hline $2-111$ & & & \begin{tabular}{|l|}
66.7 \\
\end{tabular} & 499.0 & $2-153$ & & \multirow{4}{*}{2.0} & 74.6 & 971.7 \\
\hline $2-112$ & & & \begin{tabular}{|l|}
68.3 \\
\end{tabular} & 544.5 & 2-154 & & & 73.3 & 1150.3 \\
\hline $2-113$ & & & 68.6 & 504.8 & $2-155$ & & & 71.5 & 876.1 \\
\hline $2-114$ & & & 61.0 & 360.3 & $2-156$ & & & 69.4 & 868.0 \\
\hline $2-115$ & & \multirow{6}{*}{0.50} & \begin{tabular}{|l|}
69.4 \\
\end{tabular} & 535.6 & $2-157$ & \multirow{24}{*}{$\begin{array}{l}+70 \\
\text { (US) }\end{array}$} & \multirow{4}{*}{0} & 62.4 & 1040.0 \\
\hline $2-116$ & & & \begin{tabular}{|l|}
69.9 \\
\end{tabular} & 634.1 & $2-158$ & & & 62.8 & 650.4 \\
\hline $2-117$ & & & \begin{tabular}{|l|}
69.8 \\
\end{tabular} & 591.8 & $2-159$ & & & 57.3 & 494.6 \\
\hline $2-118$ & & & 68.6 & 593.2 & $2-160$ & & & 59.0 & 924.3 \\
\hline $2-119$ & & & 70.5 & 622.2 & $2-161$ & & \multirow{4}{*}{0.15} & 63.8 & 966.0 \\
\hline $2-120$ & & & 70.6 & 582.9 & $2-162$ & & & 62.9 & 1016.7 \\
\hline $2-121$ & & \multirow{6}{*}{1.0} & - & - & $2-163$ & & & 63.8 & 1052.6 \\
\hline $2-122$ & & & 71.8 & 615.3 & $2-164$ & & & 63.2 & 1028.3 \\
\hline $2-123$ & & & \begin{tabular}{|l|}
71.8 \\
\end{tabular} & 645.6 & $2-165$ & & \multirow{4}{*}{0.25} & 58.8 & 989.2 \\
\hline $2-124$ & & & 73.9 & 723.8 & $2-166$ & & & 63.5 & 1046.9 \\
\hline $2-125$ & & & 73.8 & 746.3 & $2-167$ & & & 63.1 & 1022.1 \\
\hline $2-126$ & & & 71.7 & 629.8 & $2-168$ & & & 62.5 & 1018.6 \\
\hline 2-127 & & \multirow{6}{*}{2.0} & \begin{tabular}{|l|}
74.8 \\
\end{tabular} & 817.3 & $2-169$ & & \multirow{4}{*}{0.50} & 62.5 & 1021.8 \\
\hline $2-128$ & & & - & - & $2-170$ & & & 65.5 & 1056.3 \\
\hline $2-129$ & & & 75.0 & 866.3 & $2-171$ & & & 65.9 & 1037.2 \\
\hline $2-130$ & & & 76.8 & 878.7 & $2-172$ & & & 65.6 & 1045.6 \\
\hline $2-131$ & & & \begin{tabular}{|l|l|}
75.1 \\
\end{tabular} & 822.0 & $2-173$ & & \multirow{4}{*}{1.0} & 67.8 & 1018.5 \\
\hline $2-132$ & & & 74.6 & 804.1 & $2-174$ & & & 64.8 & 1003.6 \\
\hline $2-133$ & \multirow{6}{*}{$\begin{array}{c}+40 \\
\text { (US) }\end{array}$} & \multirow{4}{*}{0} & \begin{tabular}{|l|}
59.0 \\
\end{tabular} & 354.1 & $2-175$ & & & - & - \\
\hline $2-134$ & & & \begin{tabular}{|l|}
62.1 \\
\end{tabular} & 484.9 & $2-176$ & & & 68.3 & 1089.7 \\
\hline $2-135$ & & & \begin{tabular}{|l|}
65.2 \\
\end{tabular} & 736.9 & 2-177 & & \multirow{4}{*}{2.0} & 70.1 & 1139.5 \\
\hline $2-136$ & & & \begin{tabular}{|l|}
62.9 \\
\end{tabular} & 443.2 & $2-178$ & & & 68.7 & 1132.4 \\
\hline $2-137$ & & 0 & 64.6 & 668.3 & $2-179$ & & & 67.4 & 1073.3 \\
\hline $2-138$ & & 0.15 & 64.3 & 552.2 & $2-180$ & & & 69.2 & 1107.4 \\
\hline
\end{tabular}


Table 4. Description of specimens and experimental results. Steel S355J2.

\begin{tabular}{|c|c|c|c|c|c|c|c|c|c|}
\hline Specimen & \begin{tabular}{|c} 
Temperature \\
$\left({ }^{\circ} \mathrm{C}\right)$
\end{tabular} & $\begin{array}{c}\boldsymbol{\rho} \\
(\mathbf{m m})\end{array}$ & $\begin{array}{l}\text { LBC } \\
(\mathbf{k N})\end{array}$ & $\begin{array}{c}\mathbf{K}^{\mathbf{N}}{ }_{\text {mat }} \\
\left(\mathbf{M P a m}^{1 / 2}\right)\end{array}$ & Specimen & $\begin{array}{c}\text { Temperature } \\
\left({ }^{\circ} \mathbf{C}\right)\end{array}$ & $\begin{array}{c}\mathbf{\rho} \\
(\mathbf{m m})\end{array}$ & \begin{tabular}{|l}
$\mathbf{L B C}$ \\
$(\mathbf{k N})$
\end{tabular} & $\begin{array}{c}\mathbf{K}^{\mathbf{N}}{ }_{\text {mat }} \\
\left(\mathrm{MPam}^{1 / 2}\right)\end{array}$ \\
\hline 3-1 & \multirow{24}{*}{$\begin{array}{l}-196 \\
\text { (LS) }\end{array}$} & \multirow{4}{*}{0} & \begin{tabular}{|l|}
18.5 \\
\end{tabular} & 32.2 & 3-49 & & \multirow{4}{*}{0} & \begin{tabular}{|l|}
60.5 \\
\end{tabular} & 169.5 \\
\hline 3-2 & & & \begin{tabular}{|l|}
15.0 \\
\end{tabular} & 27.3 & $3-50$ & & & \begin{tabular}{|l|}
60.5 \\
\end{tabular} & 153.4 \\
\hline 3-3 & & & \begin{tabular}{|l|}
18.6 \\
\end{tabular} & 33.5 & 3-51 & & & \begin{tabular}{|l|}
56.2 \\
\end{tabular} & 132.6 \\
\hline 3-4 & & & \begin{tabular}{|l|}
17.9 \\
\end{tabular} & 32.1 & 3-52 & & & \begin{tabular}{|l|}
54.1 \\
\end{tabular} & 130.9 \\
\hline 3-5 & & \multirow{4}{*}{0.15} & \begin{tabular}{|l|}
26.7 \\
\end{tabular} & 46.2 & $3-53$ & & \multirow{4}{*}{0.15} & \begin{tabular}{|l|}
73.3 \\
\end{tabular} & 318.6 \\
\hline 3-6 & & & \begin{tabular}{|l|}
19.7 \\
\end{tabular} & 34.1 & $3-54$ & & & - & - \\
\hline 3-7 & & & \begin{tabular}{|l|}
27.3 \\
\end{tabular} & 47.3 & 3-55 & & & 73.2 & 300.0 \\
\hline 3-8 & & & \begin{tabular}{|l|}
34.3 \\
\end{tabular} & 59.2 & $3-56$ & & & 75.3 & 253.0 \\
\hline 3-9 & & \multirow{4}{*}{0.25} & \begin{tabular}{|l|}
33.8 \\
\end{tabular} & 58.4 & 3-57 & & \multirow{4}{*}{0.25} & - & - \\
\hline 3-10 & & & \begin{tabular}{|l|}
33.5 \\
\end{tabular} & 57.9 & $3-58$ & & & 75.1 & 297.9 \\
\hline 3-11 & & & 35.0 & 60.6 & $3-59$ & & & 73.4 & 203.4 \\
\hline 3-12 & & & 33.6 & 58.1 & $3-60$ & -120 & & \begin{tabular}{|l|}
72.9 \\
\end{tabular} & 248.8 \\
\hline 3-13 & & \multirow{4}{*}{0.50} & 47.9 & 82.9 & $3-61$ & (DBTZ) & \multirow{4}{*}{0.50} & \begin{tabular}{|l|}
77.1 \\
\end{tabular} & 241.8 \\
\hline 3-14 & & & \begin{tabular}{|l|l|}
49.9 \\
\end{tabular} & 86.3 & 3-62 & & & 79.1 & 391.7 \\
\hline $3-15$ & & & \begin{tabular}{|l|}
47.2 \\
\end{tabular} & 81.6 & 3-63 & & & 75.4 & 307.9 \\
\hline $3-16$ & & & \begin{tabular}{|l|}
40.9 \\
\end{tabular} & 70.8 & $3-64$ & & & 73.7 & 269.4 \\
\hline 3-17 & & \multirow{4}{*}{1.0} & \begin{tabular}{|l|l|}
58.7 \\
\end{tabular} & 101.4 & $3-65$ & & \multirow{4}{*}{1.0} & \begin{tabular}{|l|l|}
87.3 \\
\end{tabular} & 581.9 \\
\hline 3-18 & & & 61.5 & 106.3 & $3-66$ & & & 87.8 & 584.1 \\
\hline 3-19 & & & \begin{tabular}{|l|}
50.1 \\
\end{tabular} & 86.5 & 3-67 & & & 88.5 & 599.5 \\
\hline 3-20 & & & 63.9 & 110.5 & 3-68 & & & \begin{tabular}{|l|}
82.5 \\
\end{tabular} & 466.9 \\
\hline 3-21 & & \multirow{4}{*}{2.0} & 74.8 & 129.3 & 3-69 & & \multirow{4}{*}{2.0} & \begin{tabular}{|l|}
95.4 \\
\end{tabular} & 904.4 \\
\hline $3-22$ & & & 81.6 & 141.1 & $3-70$ & & & \begin{tabular}{|l|}
92.6 \\
\end{tabular} & 844.4 \\
\hline $3-23$ & & & \begin{tabular}{|l|}
70.1 \\
\end{tabular} & 121.2 & 3-71 & & & 94.3 & 918.0 \\
\hline $3-24$ & & & 64.6 & 111.7 & 3-72 & & & 93.7 & 950.2 \\
\hline $3-25$ & \multirow{24}{*}{$\begin{array}{c}-150 \\
\text { (DBTZ) }\end{array}$} & \multirow{4}{*}{0} & 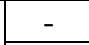 & - & 3-73 & & \multirow{6}{*}{0} & \begin{tabular}{|l|l|}
54.6 \\
\end{tabular} & 136.9 \\
\hline $3-26$ & & & 21.0 & 44.3 & 3-74 & & & \begin{tabular}{|l|}
54.6 \\
\end{tabular} & 136.1 \\
\hline 3-27 & & & \begin{tabular}{|l|}
30.4 \\
\end{tabular} & 63.3 & $3-75$ & & & \begin{tabular}{|l|}
53.1 \\
\end{tabular} & 126.8 \\
\hline 3-28 & & & \begin{tabular}{|l|}
34.4 \\
\end{tabular} & 74.1 & $3-76$ & & & \begin{tabular}{|l|}
61.5 \\
\end{tabular} & 216.6 \\
\hline 3-29 & & \multirow{4}{*}{0.15} & 71.7 & 143.2 & 3-77 & & & \begin{tabular}{|l|}
61.2 \\
\end{tabular} & 170.5 \\
\hline 3-30 & & & \begin{tabular}{|l|}
31.9 \\
\end{tabular} & 54.8 & 3-78 & & & \begin{tabular}{|l|}
55.0 \\
\end{tabular} & 158.0 \\
\hline 3-31 & & & 62.5 & 118.0 & 3-79 & & \multirow{6}{*}{0.15} & 70.6 & 236.1 \\
\hline 3-32 & & & 58.5 & 110.9 & 3-80 & & & 74.5 & 374.7 \\
\hline 3-33 & & \multirow{4}{*}{0.25} & \begin{tabular}{|l|}
65.4 \\
\end{tabular} & 126.8 & $3-81$ & & & 72.8 & 319.6 \\
\hline 3-34 & & & 78.3 & 175.8 & 3-82 & & & 73.2 & 337.8 \\
\hline 3-35 & & & \begin{tabular}{|l|}
60.2 \\
\end{tabular} & 115.1 & $3-83$ & & & \begin{tabular}{|l|}
73.3 \\
\end{tabular} & 337.8 \\
\hline 3-36 & & & - & - & 3-84 & -100 & & \begin{tabular}{|l|}
71.8 \\
\end{tabular} & 282.7 \\
\hline 3-37 & & \multirow{4}{*}{0.50} & 81.0 & 220.2 & $3-85$ & (DBTZ) & & \begin{tabular}{|l|}
75.2 \\
\end{tabular} & 412.9 \\
\hline 3-38 & & & \begin{tabular}{|l|}
77.4 \\
\end{tabular} & 341.7 & $3-86$ & & & \begin{tabular}{|l|}
75.3 \\
\end{tabular} & 390.0 \\
\hline 3-39 & & & \begin{tabular}{|l|l|}
78.7 \\
\end{tabular} & 256.9 & 3-87 & & 025 & 74.1 & 360.6 \\
\hline 3-40 & & & 76.7 & 179.0 & 3-88 & & $0.2 J$ & 74.6 & 373.5 \\
\hline $3-41$ & & & 82.4 & 266.4 & 3-89 & & & \begin{tabular}{|l|}
73.2 \\
\end{tabular} & 340.1 \\
\hline $3-42$ & & 1 & \begin{tabular}{|l|}
82.1 \\
\end{tabular} & 407.4 & 3-90 & & & \begin{tabular}{|l|}
69.7 \\
\end{tabular} & 282.8 \\
\hline $3-43$ & & 1.0 & 89.8 & 541.7 & 3-91 & & & \begin{tabular}{|l|}
71.7 \\
\end{tabular} & 326.3 \\
\hline $3-44$ & & & 82.4 & 350.5 & 3-92 & & & \begin{tabular}{|l|}
77.8 \\
\end{tabular} & 534.9 \\
\hline $3-45$ & & & \begin{tabular}{|c|}
97.0 \\
\end{tabular} & 688.7 & $3-93$ & & 050 & 79.5 & 507.5 \\
\hline $3-46$ & & & - & - & 3-94 & & 0.50 & 73.3 & 357.3 \\
\hline $3-47$ & & 2.0 & \begin{tabular}{|l|}
88.1 \\
\end{tabular} & 448.0 & $3-95$ & & & 75.4 & 383.7 \\
\hline $3-48$ & & & 80.8 & 208.8 & $3-96$ & & & \begin{tabular}{|l|}
77.9 \\
\end{tabular} & 428.8 \\
\hline
\end{tabular}


Table 4. Description of specimens and experimental results. Steel S355J2 (cont.).

\begin{tabular}{|c|c|c|c|c|c|c|c|c|c|}
\hline Specimen & $\begin{array}{c}\text { Temperature } \\
\left({ }^{\circ} \mathrm{C}\right)\end{array}$ & $\begin{array}{c}\rho \\
(\mathbf{m m})\end{array}$ & $\begin{array}{l}\text { LBC } \\
(\mathbf{k N})\end{array}$ & $\begin{array}{c}\mathbf{K}^{\mathbf{N}}{ }_{\text {mat }}{ }^{1 / 2} \\
\left(\mathrm{MPam}^{1 / 2}\right)\end{array}$ & Specimen & \begin{tabular}{|c|} 
Temperature \\
$\left({ }^{\circ} \mathrm{C}\right)$
\end{tabular} & $\begin{array}{c}\rho \\
(\mathbf{m m})\end{array}$ & \begin{tabular}{|l|}
$\mathbf{L B C}$ \\
$(\mathbf{k N})$
\end{tabular} & $\begin{array}{c}\mathbf{K}^{\mathrm{N}}{ }_{\text {mat }}{ }^{1 / 2} \\
\left(\mathbf{M P a m}^{1 / 2}\right)\end{array}$ \\
\hline 3-97 & \multirow{12}{*}{$\begin{array}{c}-100 \\
(\mathrm{DBTZ})\end{array}$} & \multirow{6}{*}{1.0} & \begin{tabular}{|l|}
87.7 \\
\end{tabular} & 629.2 & 3-127 & \multirow{6}{*}{$\begin{array}{l}-50 \\
\text { (US) }\end{array}$} & \multirow{2}{*}{1.0} & \begin{tabular}{|l|}
84.0 \\
\end{tabular} & 801.3 \\
\hline 3-98 & & & \begin{tabular}{|l|}
84.9 \\
\end{tabular} & 698.8 & $3-128$ & & & \begin{tabular}{|l|}
83.7 \\
\end{tabular} & 811.5 \\
\hline 3-99 & & & \begin{tabular}{|l|}
85.0 \\
\end{tabular} & 683.3 & 3-129 & & \multirow{4}{*}{2.0} & \begin{tabular}{|l|}
87.6 \\
\end{tabular} & 1002.4 \\
\hline $3-100$ & & & \begin{tabular}{|l|}
84.3 \\
\end{tabular} & 586.1 & 3-130 & & & \begin{tabular}{|l|}
87.9 \\
\end{tabular} & 1034.0 \\
\hline 3-101 & & & \begin{tabular}{|l|}
85.9 \\
\end{tabular} & 691.7 & 3-131 & & & \begin{tabular}{|l|}
88.1 \\
\end{tabular} & 1013.5 \\
\hline 3-102 & & & \begin{tabular}{|l|}
85.0 \\
\end{tabular} & 632.1 & 3-132 & & & \begin{tabular}{|l|}
88.7 \\
\end{tabular} & 1046.5 \\
\hline 3-103 & & \multirow{6}{*}{2.0} & \begin{tabular}{|l|}
93.3 \\
\end{tabular} & 932.9 & 3-133 & \multirow{24}{*}{$\begin{array}{c}-20 \\
\text { (US) }\end{array}$} & \multirow{4}{*}{0} & \begin{tabular}{|l|}
65.2 \\
\end{tabular} & 782.1 \\
\hline 3-104 & & & \begin{tabular}{|l|}
93.4 \\
\end{tabular} & 964.9 & 3-134 & & & \begin{tabular}{|l|}
61.3 \\
\end{tabular} & 609.1 \\
\hline 3-105 & & & \begin{tabular}{|l|}
94.1 \\
\end{tabular} & 1115.7 & 3-135 & & & \begin{tabular}{|l|}
67.7 \\
\end{tabular} & 537.0 \\
\hline 3-106 & & & \begin{tabular}{|l|}
92.4 \\
\end{tabular} & 1097.2 & 3-136 & & & \begin{tabular}{|l|}
67.4 \\
\end{tabular} & 614.3 \\
\hline 3-107 & & & \begin{tabular}{|l|}
91.8 \\
\end{tabular} & 942.4 & 3-137 & & \multirow{4}{*}{0.15} & \begin{tabular}{|l|l|}
68.8 \\
\end{tabular} & 572.4 \\
\hline 3-108 & & & - & - & 3-138 & & & \begin{tabular}{|l|}
70.5 \\
\end{tabular} & 451.0 \\
\hline 3-109 & \multirow{18}{*}{$\begin{array}{c}-50 \\
\text { (US) }\end{array}$} & \multirow{4}{*}{0} & \begin{tabular}{|l|}
69.1 \\
\end{tabular} & 491.1 & 3-139 & & & \begin{tabular}{|l|}
71.6 \\
\end{tabular} & 554.1 \\
\hline 3-110 & & & \begin{tabular}{|l|}
69.9 \\
\end{tabular} & 516.9 & $3-140$ & & & \begin{tabular}{|l|}
71.4 \\
\end{tabular} & 630.6 \\
\hline 3-111 & & & \begin{tabular}{|l|}
58.9 \\
\end{tabular} & 259.1 & 3-141 & & \multirow{4}{*}{0.25} & \begin{tabular}{|l|}
72.8 \\
\end{tabular} & 646.5 \\
\hline 3-112 & & & 60.0 & 221.4 & 3-142 & & & \begin{tabular}{|l|}
72.3 \\
\end{tabular} & 674.4 \\
\hline 3-113 & & \multirow{4}{*}{0.15} & \begin{tabular}{|l|l|}
68.9 \\
\end{tabular} & 356.1 & 3-143 & & & \begin{tabular}{|l|}
72.0 \\
\end{tabular} & 709.0 \\
\hline 3-114 & & & \begin{tabular}{|l|l|}
68.3 \\
\end{tabular} & 355.8 & 3-144 & & & \begin{tabular}{|l|}
71.8 \\
\end{tabular} & 656.0 \\
\hline 3-115 & & & \begin{tabular}{|l|}
67.4 \\
\end{tabular} & 342.7 & $2-145$ & & \multirow{4}{*}{0.50} & \begin{tabular}{|l|}
77.5 \\
\end{tabular} & 688.1 \\
\hline 3-116 & & & 69.5 & 366.2 & 3-146 & & & \begin{tabular}{|l|}
76.6 \\
\end{tabular} & 787.4 \\
\hline 3-117 & & \multirow{4}{*}{0.25} & \begin{tabular}{|l|}
74.5 \\
\end{tabular} & 512.6 & 3-147 & & & \begin{tabular}{|l|}
75.9 \\
\end{tabular} & 677.0 \\
\hline 3-118 & & & \begin{tabular}{|l|}
73.7 \\
\end{tabular} & 492.3 & 3-148 & & & \begin{tabular}{|l|}
77.0 \\
\end{tabular} & 780.7 \\
\hline 3-119 & & & \begin{tabular}{|l|l|}
74.2 \\
\end{tabular} & 519.4 & 3-149 & & \multirow{4}{*}{1.0} & \begin{tabular}{|l|}
81.5 \\
\end{tabular} & 909.9 \\
\hline 3-120 & & & 73.8 & 489.5 & $3-150$ & & & \begin{tabular}{|l|}
81.8 \\
\end{tabular} & 889.9 \\
\hline 3-121 & & \multirow{4}{*}{0.50} & \begin{tabular}{|l|}
77.1 \\
\end{tabular} & 605.4 & 3-151 & & & \begin{tabular}{|l|}
81.3 \\
\end{tabular} & 836.0 \\
\hline 3-122 & & & \begin{tabular}{|l|}
76.7 \\
\end{tabular} & 560.4 & 3-152 & & & \begin{tabular}{|l|}
80.5 \\
\end{tabular} & 759.7 \\
\hline 3-123 & & & \begin{tabular}{|l|}
77.3 \\
\end{tabular} & 550.6 & 3-153 & & \multirow{4}{*}{2.0} & \begin{tabular}{|l|}
84.9 \\
\end{tabular} & 1099.4 \\
\hline 3-124 & & & \begin{tabular}{|l|}
78.2 \\
\end{tabular} & 584.7 & 3-154 & & & \begin{tabular}{|l|}
85.8 \\
\end{tabular} & 1032.1 \\
\hline 3-125 & & \multirow{2}{*}{1.0} & \begin{tabular}{|l|}
82.6 \\
\end{tabular} & 774.0 & 3-155 & & & \begin{tabular}{|l|}
86.1 \\
\end{tabular} & 1031.2 \\
\hline 3-126 & & & \begin{tabular}{|l|}
83.3 \\
\end{tabular} & 766.9 & 3-156 & & & \begin{tabular}{|l|}
84.9 \\
\end{tabular} & 1026.1 \\
\hline
\end{tabular}

